\title{
Traumatic Neuroemergency: Imaging Patients with Traumatic Brain Injury-An Introduction
}

\author{
Paul M. Parizel and C. Douglas Philips
}

\section{Learning Objectives}

- Understand the role of imaging in the urgent evaluation of patients with CNS trauma

- Review common surgical vs. non-surgical CNS abnormalities in trauma patients

- Compare MR and CT for evaluation of brain trauma

\section{Key Points}

- CT has become the most important diagnostic test in patients with CNS trauma in the urgent setting.

- CT has the ability to depict traumatic lesions that will require urgent surgical management and to also assess other traumatic lesions that are notable but not surgical indications.

- MR can accurately detect a range of CNS injuries that are ultimately critical in the prognosis of major CNS trauma.

\subsection{Introduction}

Traumatic brain injury (TBI) remains a leading cause of mortality and disability among young individuals, especially in high-income countries [1]. According to a meta-analysis, combining reports from 23 European countries between

\section{P. M. Parizel}

Department of Radiology, Antwerp University Hospital, Faculty of Medicine and Health Sciences, University of Antwerp,

Antwerp, Belgium

C. D. Philips $(\square)$

Weill Cornell Medical Center, NewYork-Presbyterian Hospital,

New York, NY, USA

e-mail: dphillips@med.cornell.edu
1980 and 2003, the incidence rate is about 235 per 100,000 [2]. Increasingly, imaging techniques play a crucial role in the diagnosis and management of patients with craniocerebral trauma, and may influence life or death decisions. Additionally, the role of imaging in the prediction of prognosis is well established and of growing importance in the research arena.

\subsection{Imaging Techniques}

We have moved well beyond the era of projectional radiography, as the diagnostic efficacy of plain skull films in TBI is poor. At present, for the management of patients with traumatic brain injury, plain X-ray films play no role; they have entirely been replaced by computed tomography (CT) imaging [3].

$\mathrm{CT}$ is the initial imaging technique for evaluation of craniocerebral trauma. In most trauma centers and emergency rooms, CT is readily available and available within a short distance from the trauma bay. Many emergency departments routinely position one or several CT scanners in the receiving area for triage. Moreover, a CT examination can be performed in a few seconds with a modern, state-ofthe-art multi-detector CT (MDCT) scanner. MDCT allows acquisition of multiple thin sections in a much shorter scan time than a single-detector system [4] and has essentially replaced them. Image data can be reconstructed in every plane as well as in 3D views (Fig. 7.1). Routine utilization of these multiplanar reconstructed (MPR) images also appears to improve diagnosis of traumatic injuries and has been supported in the literature to increase CT accuracy [5]. Cranial CT is used for evaluation of all forms of intracranial hemorrhage, fractures, brain edema, herniation and other associated injuries, as well as to evaluate foreign bodies. CT angiography (dynamic contrast-enhanced CT to visualize vascular structures) may be indicated whenever vascular injury is suspected, and also patients with a highrisk mechanism trauma, such as, for example, intra-oral 


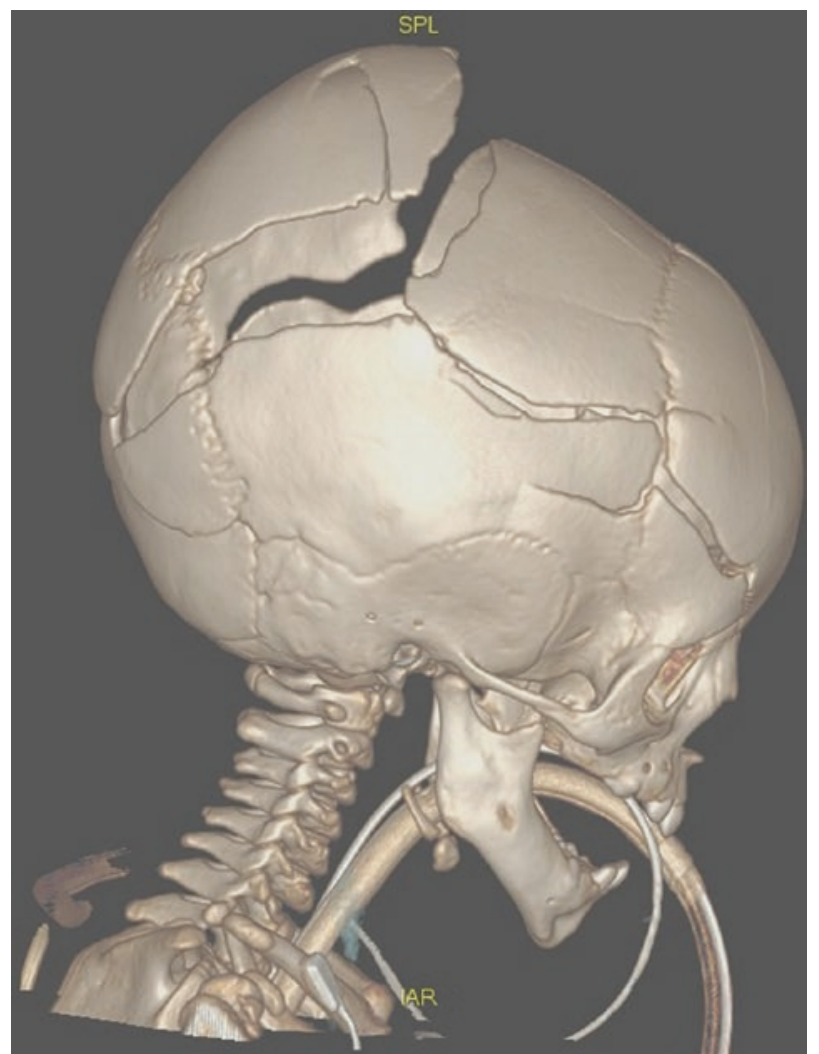

Fig. 7.1 Volume rendering technique (VRT), obtained from a 3D CT-scan data set, reveals multiple skull fractures and displaced bone fragments. The sharp outline of the fracture lines is clearly distinct from the jagged and serrated edges of the cranial sutures in this young child with severe craniocerebral trauma

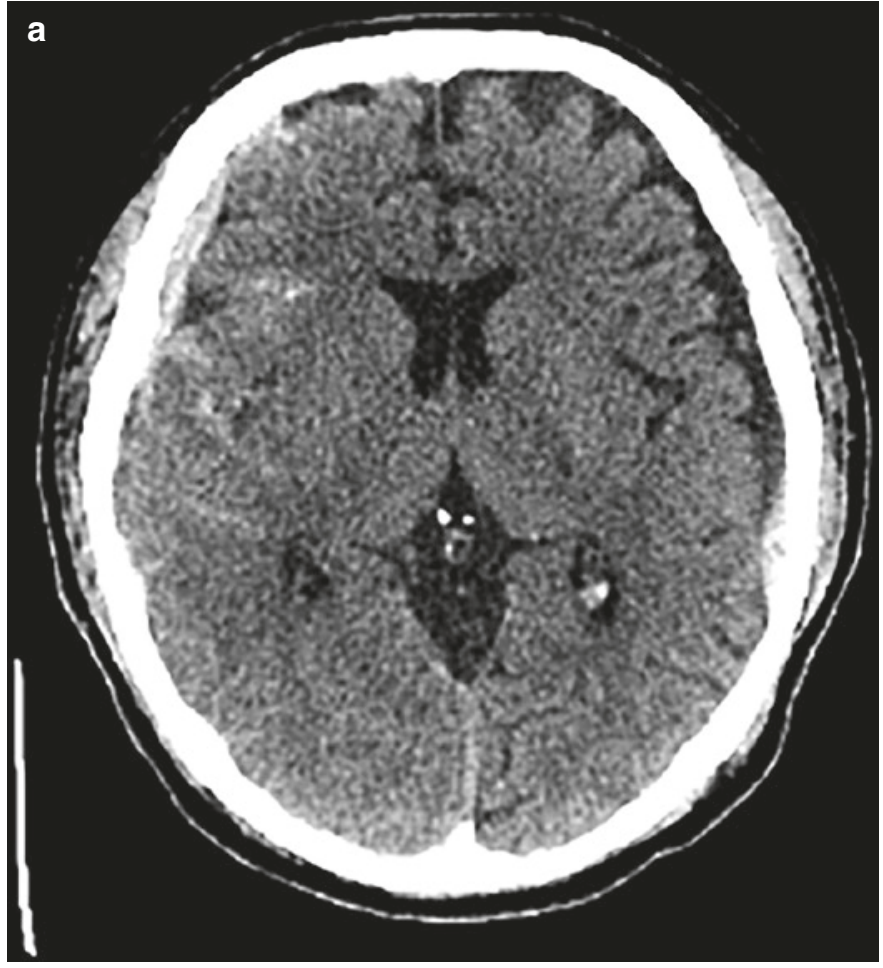

Fig. 7.2 (a, b) Axial non-contrast CT-scan, revealing a left parietal epidural hematoma ("coup" side) with accompanying subarachnoid hemorrhage. A fracture was evident on bone images. On the "contre- trauma, high energy crashes, near-hanging, and fractures of skull base and midface [6] or for suspicious hemorrhage patterns.

MRI is more sensitive than $\mathrm{CT}$ for the detection of parenchymal lesions [7, 8]. It is also indicated whenever there is a discrepancy between the clinical neurological status of the patient and the CT findings.

In this review paper, we aim to present a systematic guide towards interpretation of imaging studies in the patient with TBI.

\subsection{Scalp Lesions}

Scalp lesions are common in head trauma victims (Figs. 7.2 and 7.3). Although they are of little clinical importance, identification of scalp lesions may direct the attention of the radiologist towards the point of impact [9]. CT is rarely performed for isolated scalp injury, but to detect the suspected intracranial injuries. CT not only visualizes the soft tissue swelling, but through appropriate window (W) and level (L) settings will also illustrate intracranial abnormalities [8]. One important factor influencing the detection rate of soft tissue lesions in CT is the perception of density differences within the lesions and the surrounding tissues such as blood, subcutaneous fatty tissue, or cerebrospinal fluid [10].

Table 7.1 provides an overview of some of the most commonly encountered scalp lesions.

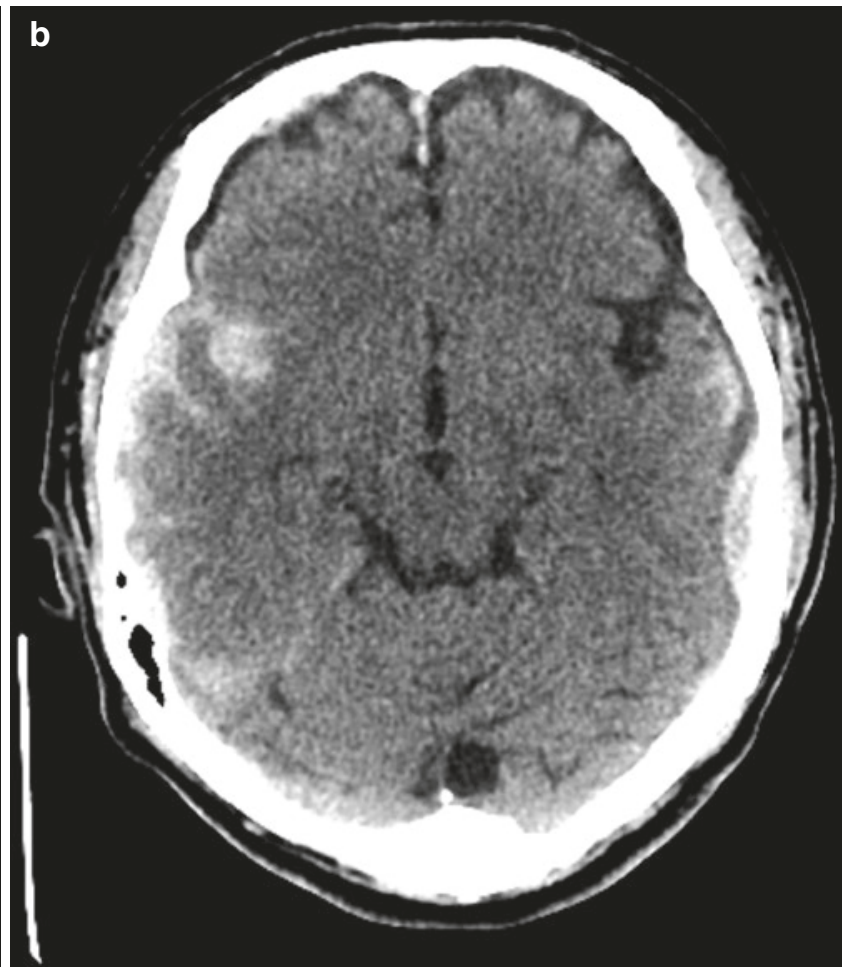

coup" side, there is a hyperdense subdural hematoma overlying the right cerebral hemisphere, as well as a basifrontal hemorrhagic contusion 

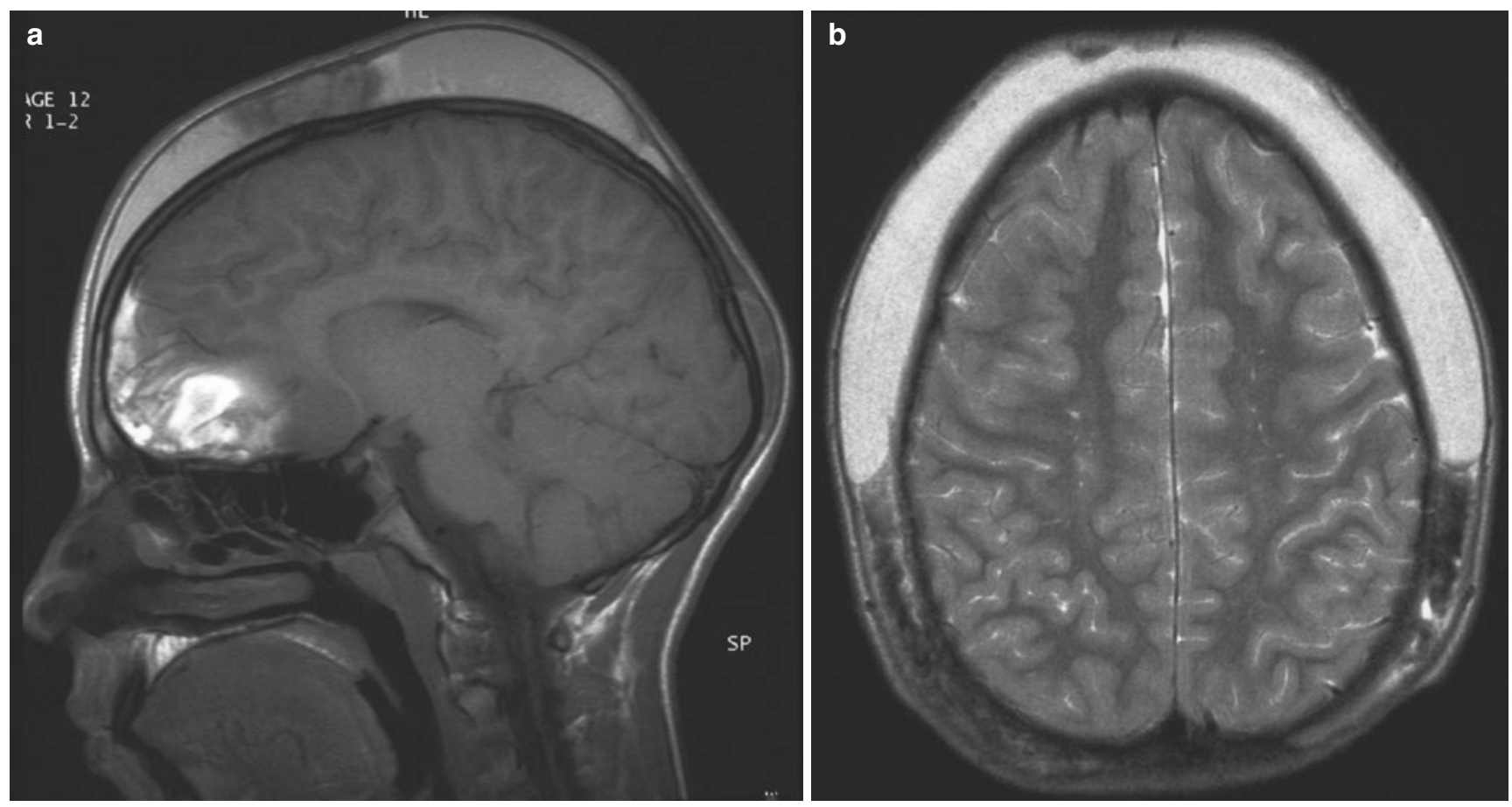

Fig. 7.3 (a, b) Hemorrhagic cerebral contusions and subgaleal hematoma. MRI examination performed with (a) sagittal SE T1-weighted images and (b) axial TSE T2-weighted images. Extracranially, there is marked swelling of the subcutaneous soft tissues, due to a massive sub- galeal hematoma, which extends from the frontal to the posterior parietal region. Intracranially, there are hemorrhagic cerebral contusions in the right frontal and anterior temporal lobes

Table 7.1 Overview of scalp lesions

\begin{tabular}{|c|c|c|c|c|}
\hline Lesion type & Caput succedaneum & $\begin{array}{l}\text { Subgaleal hematoma (extracranial } \\
\text { subdural hematoma) }\end{array}$ & Subgaleal hygroma & $\begin{array}{l}\text { Cephalohematoma (extracranial } \\
\text { epidural hematoma) }\end{array}$ \\
\hline Occurrence & $\begin{array}{l}\text { After normal vaginal } \\
\text { delivery }\end{array}$ & After head trauma (or after birth) & $\begin{array}{l}\text { Birth trauma } \\
\text { (forceps delivery) }\end{array}$ & $\begin{array}{l}\text { Birth trauma (skull fracture during } \\
\text { birth) }\end{array}$ \\
\hline Location & $\begin{array}{l}\text { Superficial of the galea } \\
\text { aponeurotica }\end{array}$ & Beneath the galea aponeurotica & $\begin{array}{l}\text { Beneath the galea } \\
\text { aponeurotica }\end{array}$ & Subperiosteal (flat skull bones) \\
\hline Composition & $\begin{array}{l}\text { Edema (with microscopic } \\
\text { hemorrhages) }\end{array}$ & Venous blood & Cerebrospinal fluid & Subperiosteal hemorrhage \\
\hline Clinical presentation & Pitting edema & $\begin{array}{l}\text { Diffusely spreading, firm } \\
\text { fluctuating mass }\end{array}$ & - & Well defined, focal, firm mass \\
\hline Skull fracture & & Yes or no & Yes & Yes \\
\hline Crosses suture lines? & Yes & Yes & Yes & No \\
\hline
\end{tabular}

\subsection{Skull Fractures}

Skull fractures constitute a diverse group of traumatic bone injuries with different mechanism of occurrence, topography, complications, and required management. They can be classified according to various parameters:

- Shape of the fracture: linear, comminuted, stellate

- Depressed, non-depressed, open

- Anatomic location and extent of the fracture: skull vault, skull base, craniofacial junction

Simple linear fractures are most common type, especially in children younger than 5 years. Temporal bone fractures represent $15-48 \%$ of all skull fractures and are considered as a separate category of skull injury. Skull base and temporal bone fractures have their own clinical significance; a detailed discussion of these injuries is beyond the scope of this text.

CSF leaks, cranial nerve injuries, orbital injuries, and craniocervical junction injuries are common accompaniments of fractures, especially near the skull base.

Depressed skull fractures (with displacement of the outer table of the skull to at least the level of the inner table) occur in $75 \%$ of cases in the frontoparietal region and are often open (75-90\%).

Patients with skull fractures have a fivefold increased risk of having an intracranial hemorrhage (ICH) and CT is mandatory [11]. Linear skull fractures may be occult on skull radiographs because of the double-layered skull along fractures, when the cross-section is oblique to the direction of the X-rays [12]. Similarly, skull fractures may be difficult to see on CT, particu- 
Table 7.2 Epidural versus subdural hematoma

Epidural hematoma (EDH)
'Coup' side
Associated with skull fracture in $\pm 90 \%$ of cases
Does not cross suture lines
Not limited by falx or tentorium (may extend from supra- to
infratentorial or across midline)
Origin
- Arterial (majority, due to tearing of one or more branches of the
meningeal arteries, most commonly the middle meningeal artery),
- Venous (minority, due to laceration of a dural venous sinus,
e.g., along the sphenoparietal sinus)
Medical emergency
Magnitude of the mass effect caused by EDH is directly related
to the size of the extracerebral collection
CT is preferred imaging technique because
- Rapid accessibility
- Shows both the hemorrhage and the skull fracture
MR can be useful for
- Detection of parenchymal repercussions (edema, mass effect,
herniations)

larly when parallel to the display plane. The interpreting physician may need to correlate MPR images as well as occasionally rely on the scout image to depict these linear fractures.

In patients with significant TBI, skull fractures are common and are often overlooked on clinical examination. However, in some cases, there is a poor correlation between skull fractures and intracranial injury; severe brain injuries can occur, even without the presence of a skull fracture [8].

\subsection{Extra-Axial Lesions}

There are four types of extra-axial hemorrhage to be considered: epidural, subdural, subarachnoid, and intraventricular.

\subsubsection{Epidural Hematoma}

Epidural hematoma (EDH) is an extracerebral collection of blood between the inner table of the skull and the dura, essentially underlying a bare bone surface. EDH occurs in $<1 \%$ of patients with head injuries [13]. EDH is typically found on the "coup" injury side, and is commonly associated with a skull fracture and laceration of the underlying blood vessel(s), notably the dural vasculature [14]. The recommended imaging method is CT, which depicts both the fracture and resulting hemorrhage. EDHs are commonly biconvex in appearance and typically do not cross suture lines but may cross the tentorium or falx; their mass effect is mostly caused by the size of extracerebral collection [14]. In the early stage, an epidural hematoma may appear heterogeneous on CT with hyperdense areas of clotted blood and hypodense whirls of non-coagulated blood that in time becomes more homogeneous [14]. This "swirl sign" is an ominous feature, and should be carefully noted and communicated to the treating physicians, as it represents active hemorrhage into the collection [15]. Rapid progression has been noted.

\section{Subdural hematoma (SDH)}

\section{'Contre-coup' side}

No consistent relationship with skull fractures

Does cross suture lines

Limited by falx and tentorium (confined to supra- or infratentorial compartment, does not cross midline)

Origin

- Venous, due to laceration of superficial bridging cortical veins

May be chronic

Magnitude of the mass effect caused by SDH is more often associated with underlying parenchymal injury MRI is preferred imaging technique because

- MRI is more sensitive than CT, especially in the detection of so-called isodense SDH's which may be difficult to see on CT

- Multiplanar imaging capability

- Better definition of multi-compartmental nature of SDH

EDH may be arterial or venous in origin (Table 7.2). Arterial EDH is caused by injury of a meningeal artery, commonly the middle meningeal artery. The typical location is the temporoparietal region, with $75 \%$ of EDH occurring adjacent to the temporal bone (Fig. 7.4). When the blood vessel is lacerated, arterial bleeding results in a rapidly expanding hematoma that exerts mass effect on the brain, focal deformity of the brain and an increase in intracranial pressure (ICP). The size of the EDH may continue to increase until the arterial perfusion pressure is equilibrated with the elevated ICP. Emergency decompressive surgery is indicated to remove the $\mathrm{EDH}$, stop hemorrhage, and reduce compression on the brain.

Venous EDH results from rupture/laceration of a dural venous sinus, or bleeding from diploic veins, again often associated with a skull fracture [16]. Venous EDH is usually located near the anterior wall of the middle cranial fossa (injury of sphenoparietal sinus and/or fracture of the greater wing of the sphenoid bone), the vertex (injury of the superior sagittal sinus and/or fracture of the frontal or parietal bone), or against the occiput near the tentorium (injury of the transverse sinus and/or occipital fracture) [8] (Fig. 7.5).

Few EDH patients will not undergo craniotomy and evacuation, often on an emergent basis. One unusual and typically indolent EDH is known; anterior temporal EDH is often a lowpressure hemorrhage and typically do not expand. There is no usual requirement for surgical intervention [16]. Conversely, posterior fossa EDH may urgently require surgical evacuation because of early brainstem compression [16].

\subsubsection{Subdural Hematoma}

A subdural hematoma (SDH) represents an extracerebral collection of blood in the potential space between the dura mater and the arachnoid membrane, or "epiarachnoid." 


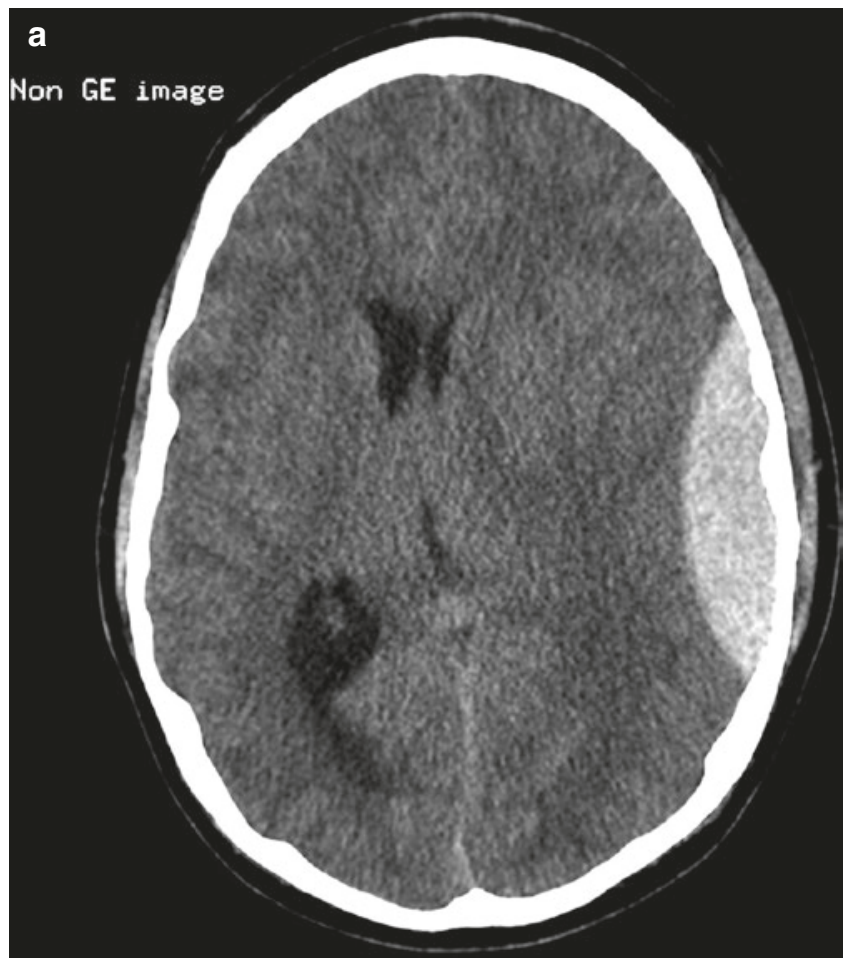

Fig. 7.4 (a, b) Acute left arterial epidural hematoma. Non-contrast CT-scan upon admission. The left-sided hematoma is biconvex, and is limited by the coronal suture anteriorly and by the lambdoid suture pos-

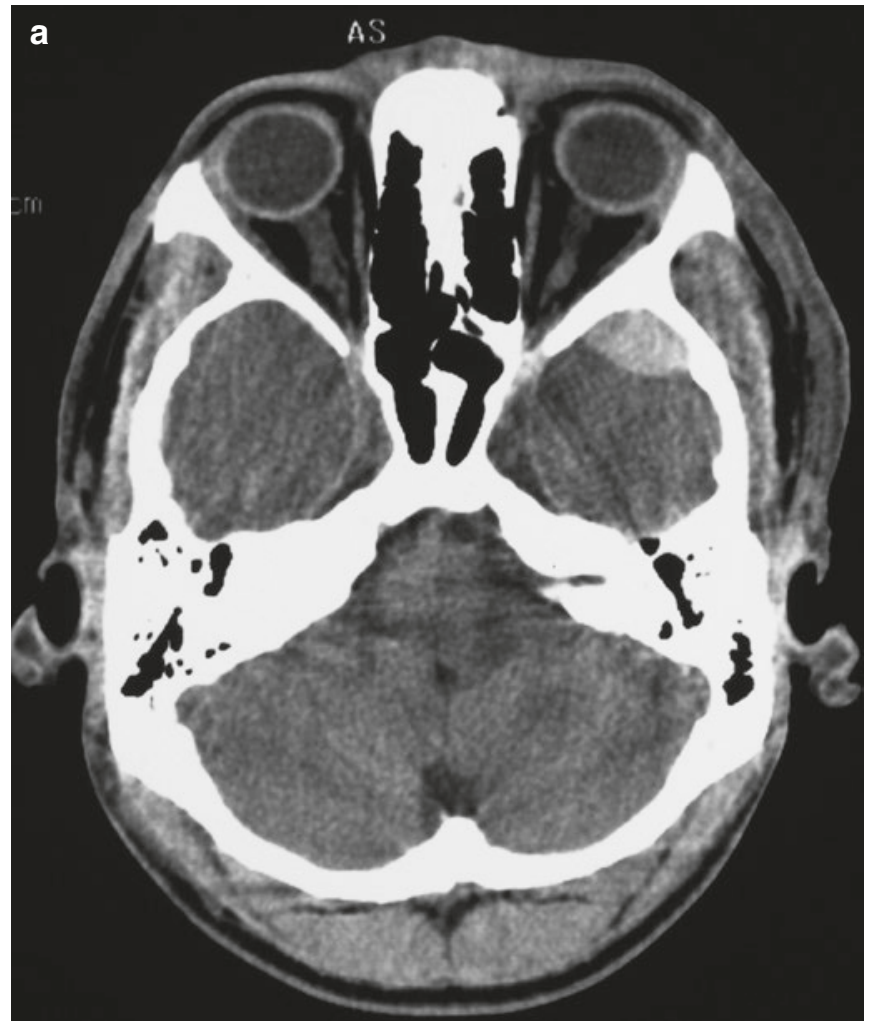

Fig. 7.5 (a, b) Venous epidural hematomas, shown in two different patients. Venous epidural hematomas typically are found (a) anteriorly in the middle cranial fossa adjacent to the sphenoparietal sinus and

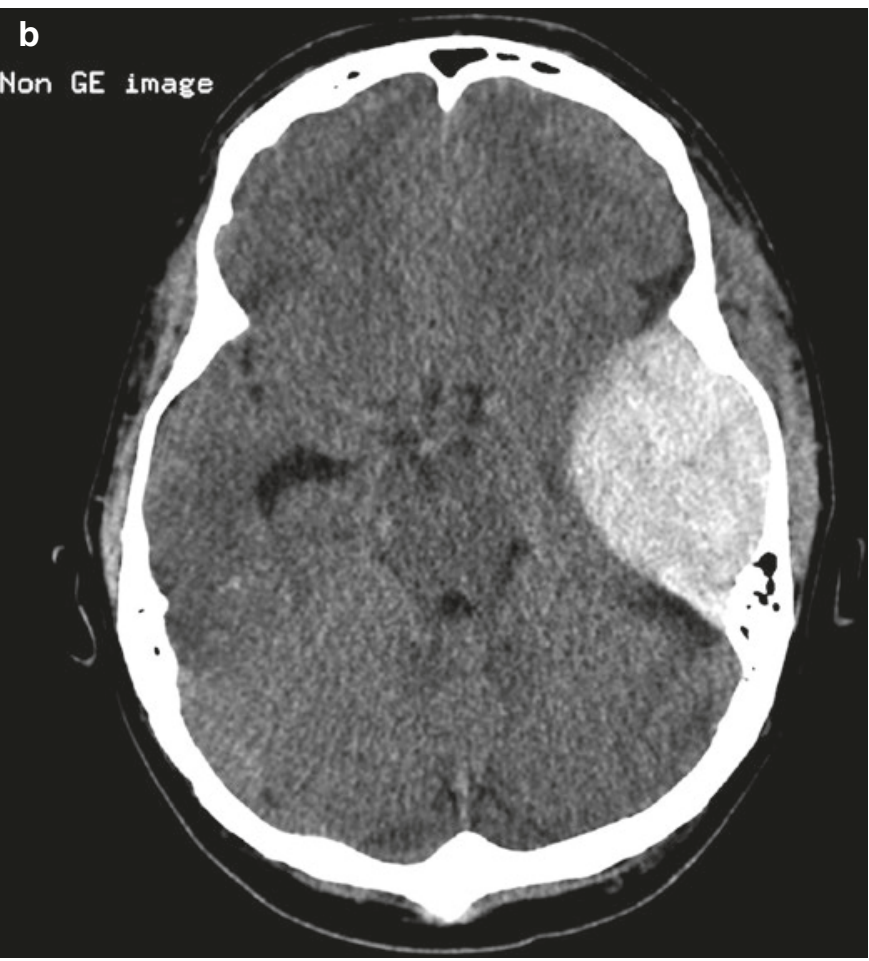

teriorly. The mass effect causes a shift of the midline structures with compression of the left lateral ventricle and dilatation of the right lateral ventricle

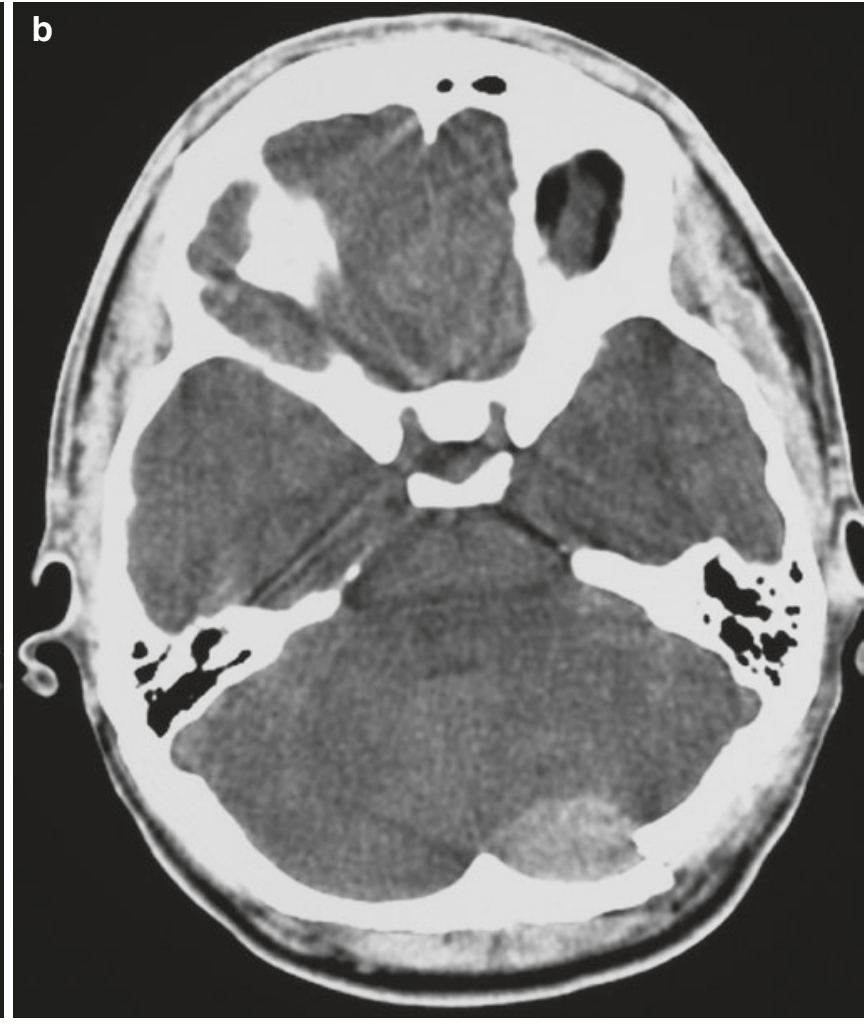

greater wing of the sphenoid bone, or (b) adjacent to the transverse sinus. They present a typical, biconvex lens-shaped configuration 
SDHs are relatively common and occur in about $30 \%$ cases of severe head trauma [13]. They are more commonly found on the contre-coup injury side and are not as strongly associated with fractures as EDH [14]. The origin is almost invariably venous, caused by injury of superficial bridging cortical veins. They do cross sutures and may be holohemispheric, and are typically limited by the falx and tentorium [14].

On CT, an acute SDH is seen as crescentic hyperdense structure between brain and the inner border of skull (Fig. 7.6). On modern CT scanners, the arachnoid space may
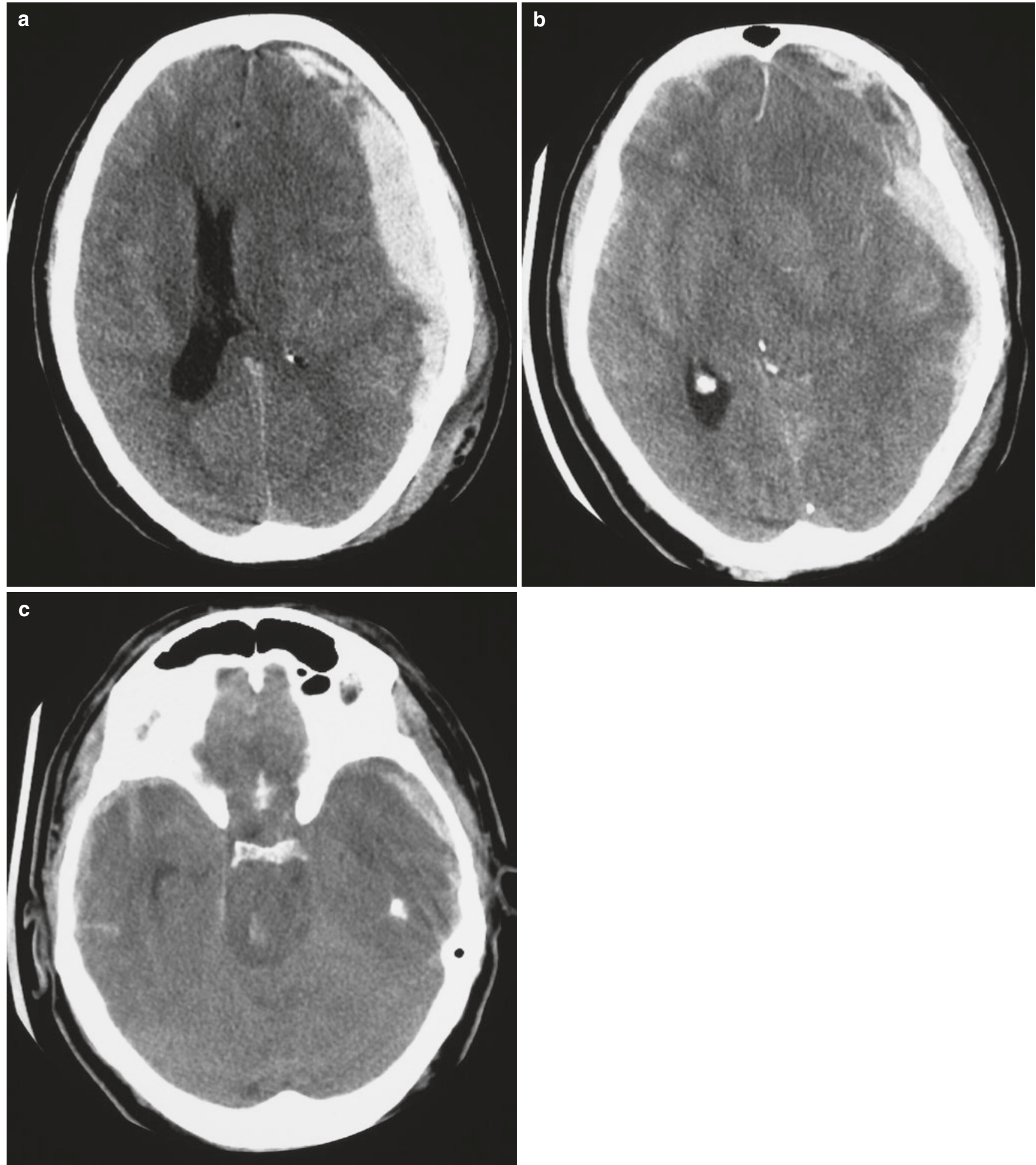

Fig. 7.6 (a-c) Acute left subdural hematoma. The CT-scan shows hyperdense areas of clotted blood and some hypodense components indicating active bleeding. There is mass effect on the left cerebral hemisphere, with transtentorial herniation. The high-density area in the

brainstem indicates a secondary brainstem hemorrhage or so-called Duret hemorrhage. There are also hemorrhagic cerebral contusions in both cerebral hemispheres 

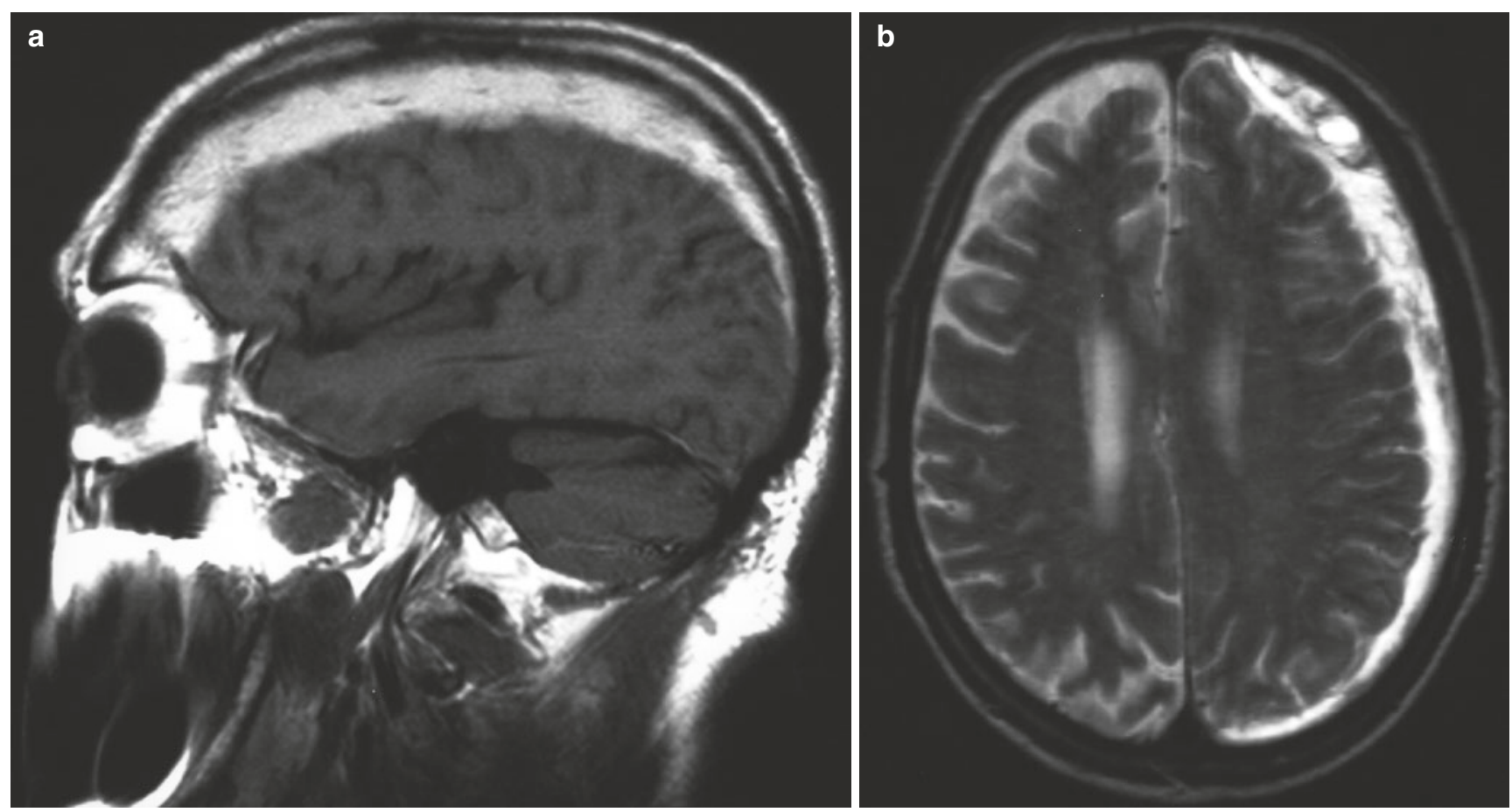

Fig. 7.7 (a, b) Subacute left subdural hematoma. MRI examination performed with (a) sagittal SE T1-weighted image and (b) axial TSE T2-weighted image. The MR images show the typical appearance of a crescent-shaped left subdural hematoma. There are multiple internal septations, representing strands of fibrovascular granulation tissue, derived from the inner (meningeal) layer of the dura. The hematoma extends over the surface of the left cerebral hemisphere from the frontal to the occipital region. The blood is hyperintense on T1-WI and on T2-WI, indicating the presence of extracellular methemoglobin be seen adjacent to the brain opposing the SDH. SDHs do not penetrate into sulci. Over time, the density decreases and they may become isodense to the adjacent brain. Therefore, MRI may be a preferred imaging method in later stages.

Subacute SDH occurs as hyperintense lesion on T1 and T2-weighed images due to extracellular methemoglobin [17] (Fig. 7.7). Chronic subdural hematoma is also well evaluated by MRI, which can clearly distinguish the size and extent of the collection as well as the development of the enhancing, capillary-rich membrane associated with resorbing SDH [17]. Chronic subdural hematomas are variable in signal but may retain T1 or FLAIR hyperintensity (Fig. 7.8).

The development of the vascular membranes, that are common in chronic SDH, is an important feature in the subsequent development of rehemorrhage into these collections, representing the "acute on chronic" form of $\mathrm{SDH}$. These collections may appear quite complex in nature, with mixed and layered signal intensities, and are difficult to manage [18].

Finally, the occasional occurrence of an acute low-density subdural collection in the trauma patient is a known phenomenon. A tear in the arachnoid may allow CSF to enter the potential subdural space and produce an enlarging fluid collec- tion known as a subdural hygroma. These may spontaneously resolve but also are monitored for mass effect.

\subsubsection{Traumatic Subarachnoid Hemorrhage}

Traumatic subarachnoid hemorrhage (SAH) is common and often focal. It can be due to superficial cerebral abrasions, direct leptomeningeal vascular injury, or intraventricular hemorrhage with subarachnoid reflux [8]. The estimated incidence rates for SAH are 10-25 per 100,000 per year [19]. Acute SAH is easy recognizable on non-contrast CT as gyriform high attenuation in the subarachnoid space. It will penetrate sulci. The attenuation of blood on CT decreases as the hemoglobin concentration decreases [20]. The combination of SWI and FLAIR yields a distinctly higher detection rate for SAH due to their complementary detection capabilities [21]. FLAIR is sensitive for superficial/convexity SAH, while SWI adds value for the centrally located SAH, e.g., the interhemispheric fissure, interpeduncular fossa, supracerebellar cistern, and intraventricular subarachnoid blood [21]. The recognition of subtle SAH is important in the trauma setting, as this finding alone will typically result in an extended in-hospital evaluation of the patient. 


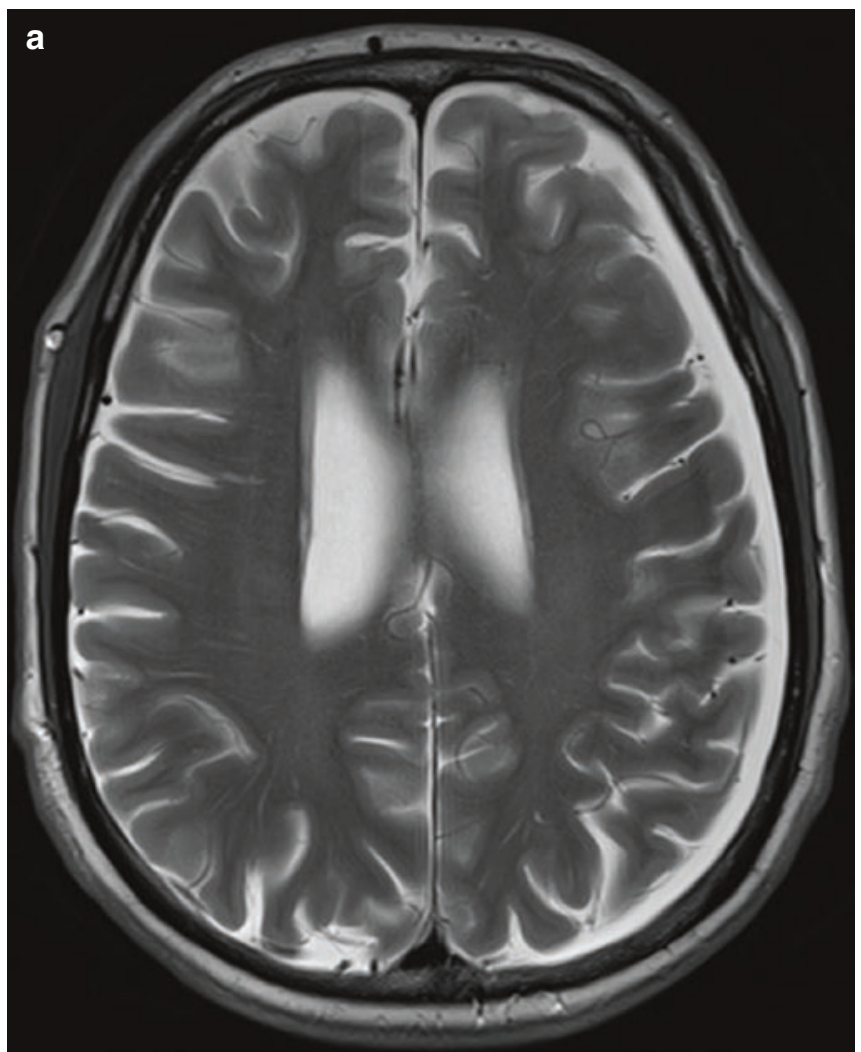

Fig. 7.8 (a, b) Chronic left subdural hematoma. MRI examination, including (a) axial TSE T2-weighted image and (b) axial turbo-FLAIR image with fat saturation. On the T2-weighted scan, the chronic subdural hematoma overlying the left cerebral hemisphere is hyperintense,

\subsubsection{Traumatic Intraventricular Hemorrhage}

Traumatic intraventricular hemorrhage (IVH) occurs as a result of the tearing of subependymal or choroidal veins or reflux of SAH into the ventricular system. It may also be seen in association with diffuse axonal injury of the corpus callosum. The incidence of IVH in nonpenetrating head injury is $1.5-3 \%$ and $10-25 \%$ of patients with severe head injury [22].

On CT IVH may appear as a hyperdense collection in the ventricular system. MRI is more sensitive to IVH and DWI and FLAIR are the preferred sequences for identifying IVH (Fig. 7.9). During the first $48 \mathrm{~h} \mathrm{IVH} \mathrm{appears} \mathrm{hyperintense} \mathrm{on}$ FLAIR, but subsequently the signal intensity may be variable [23]. Pulsatile flow artifacts in the third and fourth ventricle may compromise the usefulness of the FLAIR technique [8]. 3D-FLAIR techniques are more useful in this regard. SWI is extremely sensitive in detecting intraventricular hemorrhage. IVH appears as a typical hypointense area of susceptibility [24].

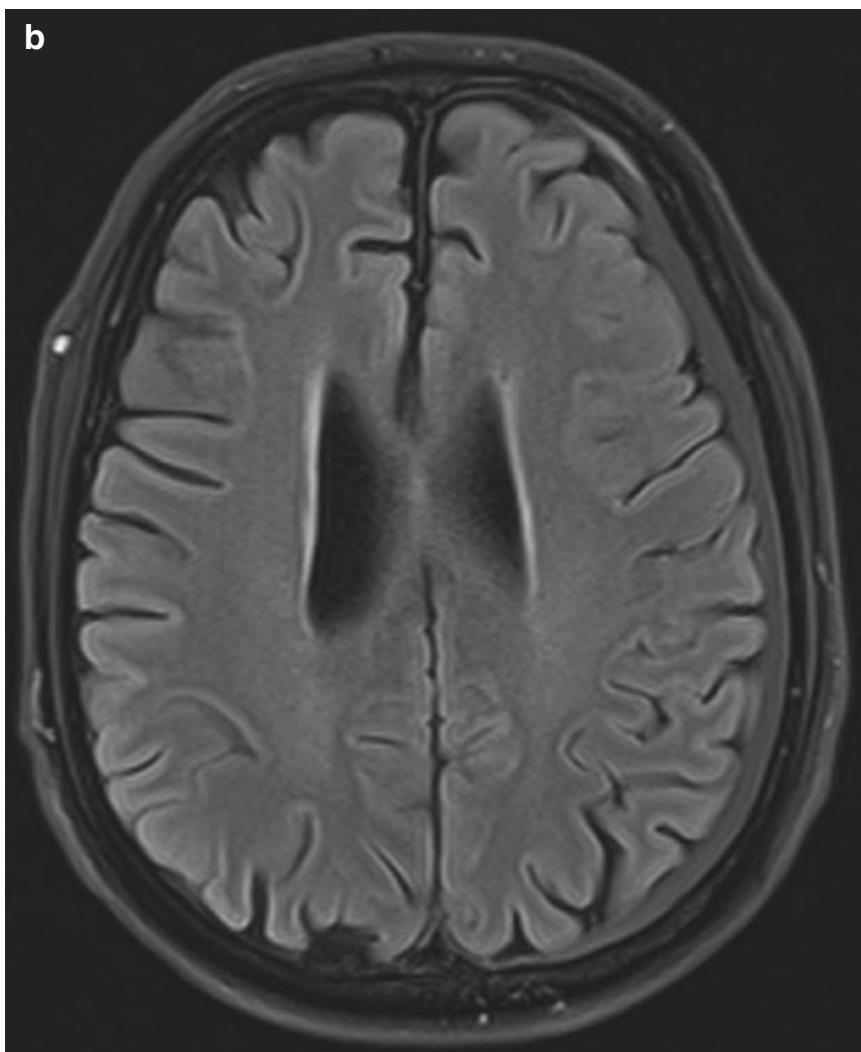

and appears isointense to cerebrospinal fluid (CSF); however, on the FLAIR image, the signal intensity is higher than CSF, indicating a different protein content

\subsection{Intra-Axial Lesions}

\subsubsection{Cerebral Contusion, Hemorrhagic Vs Non-hemorrhagic, Coup Versus Contre-Coup}

Cerebral contusions are focal injuries of the brain surface due to direct impact with the skull and are most common at sides of bony protuberances or overlying irregular areas of the floor of the anterior or middle fossa. They are, in essence, to be considered as "a bruise of the brain." The consequent lesions are hemorrhagic or edematous and may progress to necrosis [25].

All contusions are hemorrhagic, but the extent of edema versus hemorrhage in an individual contusion will determine its appearance on CT. MR will consistently depict hemorrhage, notably on SWI or GRE sequences. Hemorrhagic contusions are superficial and have either a "salt-and-pepper" appearance or may appear more solid [26]. When a traumatic brain injury results in a cerebral contusion, they may prog- 


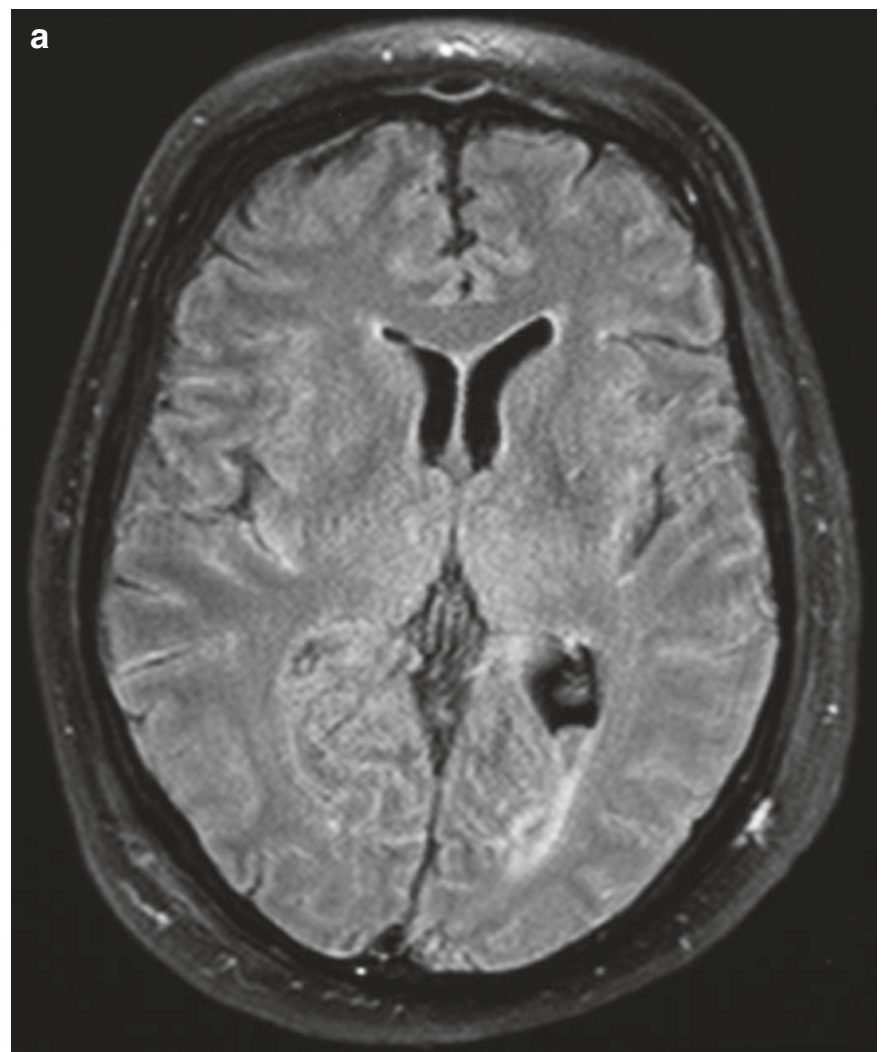

Fig. 7.9 (a, b) Posttraumatic intraventricular and subarachnoid hemorrhage. MRI examination, including (a) axial turbo-FLAIR image with fat saturation and (b) axial diffusion-weighted trace image $(b=1000)$. In the left occipital horn, there is intraventricular blood, with a hemor-

ress during the first several hours and can be associated with SAH [27]. Predominantly affected areas are located in the supratentorial region-anterior frontal and temporal lobes and the gyri around the Sylvian fissure.

On CT, hemorrhagic contusions appear as heterogeneous, hyperdense cortical lesions surrounded by an irregularly marginated hypodense (edematous) component. In the acute stage, CT may be more sensitive than MRI, as acute hemorrhage can be nearly indistinguishable from brain parenchyma on MRI. Subsequent CT performed between 24 and $48 \mathrm{~h}$ after traumatic brain injury often demonstrates previously undetected contusions or more extensive hemorrhage and increased edema. MRI is more sensitive than CT to depict cerebral contusions after the first $24 \mathrm{~h}$ because of the visualization of "non-hemorrhagic" contusion, or contusions with predominant edema. This is particularly true of FLAIR $[8,25]$. The ability of MRI to detect hemorrhagic brain lesions increases proportionally to the evolution of blood products in these lesions. Hemosiderin and also deoxyhemoglobin have increased magnetic susceptibility that make SWI or T2*

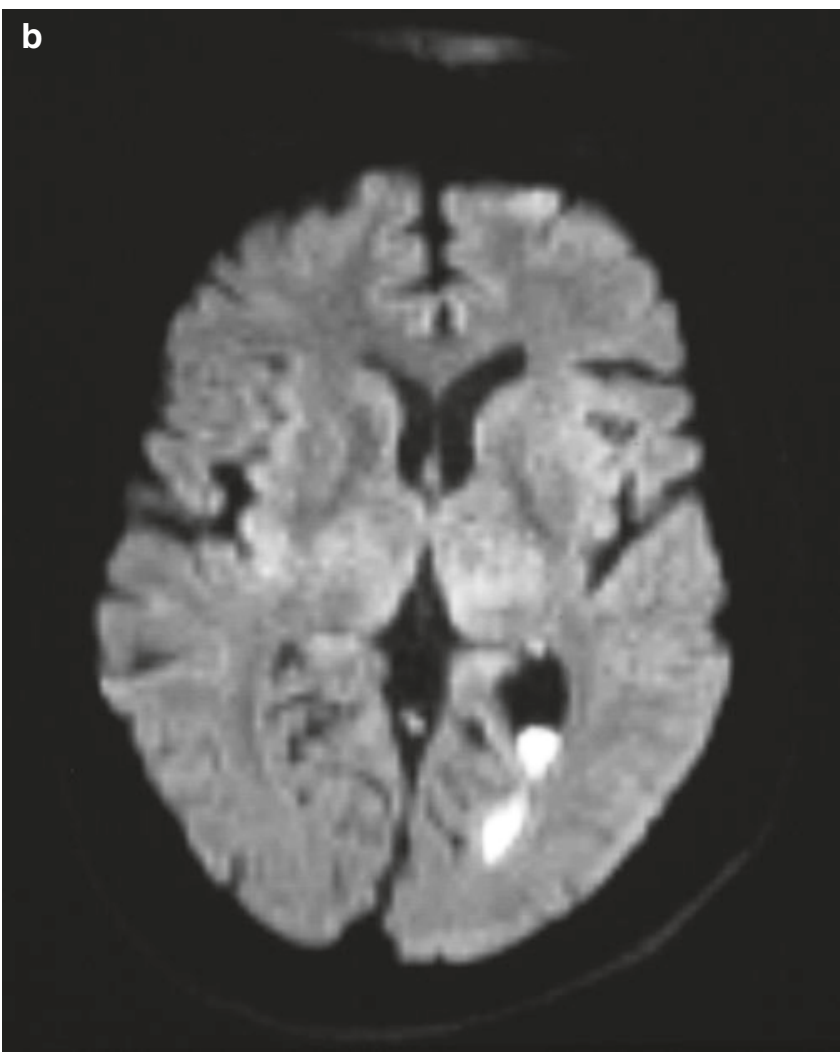

rhagic sedimentation level, and markedly restricted diffusion. In addition, there is evidence of subarachnoid hemorrhage, best seen on the FLAIR images

gradient-echo sequences very sensitive for detecting hemorrhagic lesions [28, 29]. Four to six months after injury the lesions become cystic and lose volume and therefore hypodense on CT [30], although MR findings of hemorrhage persist.

Table 7.3 provides an overview of sequential signal intensity changes of intracranial hemorrhage on MRI.

Contusions may be bihemispheric and occur along the vector of the force applied to the skull on the site of impact and the opposite region of brain. These injuries are referred to as "coup" (side of injury) or "contre-coup" (opposite the injury). In closed-head injury, for example, after an abrupt stop, the force translation can result in this pattern [30]. The coup-injury is on the side of primary impact, often identified by scalp lesions or skull fracture. "Contre-coup" lesions are the mechanical consequence of an acceleration/deceleration trauma and occur on the opposite side of impact. They are often larger and more extensive than the coup lesions, perhaps because of the initial displacement of the brain toward the contre-coup location $[8,30,31]$. 
Table 7.3 Sequential signal intensity changes of intracranial hemorrhage on MRI (1,5 T)

\begin{tabular}{|c|c|c|c|c|c|}
\hline & Hyperacute hemorrhage & Acute hemorrhage & $\begin{array}{l}\text { Early subacute } \\
\text { hemorrhage }\end{array}$ & $\begin{array}{l}\text { Late subacute } \\
\text { hemorrhage }\end{array}$ & Chronic hemorrhage \\
\hline $\begin{array}{l}\text { What } \\
\text { happens }\end{array}$ & $\begin{array}{l}\text { Blood leaves the } \\
\text { vascular system } \\
\text { (extravasation) }\end{array}$ & $\begin{array}{l}\text { Deoxygenation with } \\
\text { formation of deoxy-Hb }\end{array}$ & $\begin{array}{l}\text { Clot retraction and } \\
\text { deoxy-Hb is oxidized to } \\
\text { met-Hb }\end{array}$ & $\begin{array}{l}\text { Cell lysis (membrane } \\
\text { disruption) }\end{array}$ & $\begin{array}{l}\text { Macrophages digest the } \\
\text { clot }\end{array}$ \\
\hline Time frame & $<12 \mathrm{~h}$ & $\begin{array}{l}\text { Hours-days (weeks in } \\
\text { center of hematoma) }\end{array}$ & A few days & 4-7 days -1 month & Weeks-years \\
\hline $\begin{array}{l}\text { Red blood } \\
\text { cells }\end{array}$ & Intact erythrocytes & $\begin{array}{l}\text { Intact, but hypoxic } \\
\text { erythrocytes }\end{array}$ & $\begin{array}{l}\text { Still intact, severely } \\
\text { hypoxic }\end{array}$ & $\begin{array}{l}\text { Lysis (solution of } \\
\text { lysed cells) }\end{array}$ & $\begin{array}{l}\text { Gone; encephalomalacia } \\
\text { with proteinaceous fluid }\end{array}$ \\
\hline State of $\mathrm{Hb}$ & $\begin{array}{l}\text { Intracellular oxy-Hb } \\
(\mathrm{HbO} 2)\end{array}$ & $\begin{array}{l}\text { Intracellular deoxy-Hb } \\
(\mathrm{Hb})\end{array}$ & $\begin{array}{l}\text { Intracell. met-Hb } \\
(\mathrm{HbOH})(\text { first at } \\
\text { periphery of clot) }\end{array}$ & $\begin{array}{l}\text { Extracell. met-Hb } \\
(\mathrm{HbOH})\end{array}$ & $\begin{array}{l}\text { Hemosiderin (insoluble) } \\
\text { and ferritin (water soluble) }\end{array}$ \\
\hline $\begin{array}{l}\text { Oxidation } \\
\text { state }\end{array}$ & $\begin{array}{l}\text { Ferrous }(\mathrm{Fe} 2+) \\
\text { No unpaired e- }\end{array}$ & $\begin{array}{l}\text { Ferrous }(\mathrm{Fe} 2+) \\
4 \text { unpaired e- }\end{array}$ & $\begin{array}{l}\text { Ferric }(\mathrm{Fe} 3+) \\
5 \text { unpaired e- }\end{array}$ & $\begin{array}{l}\text { Ferric }(\mathrm{Fe} 3+) \\
5 \text { unpaired e- }\end{array}$ & $\begin{array}{l}\text { Ferric }(\mathrm{Fe} 3+) \\
2000 \times 5 \text { unpaired e- }\end{array}$ \\
\hline $\begin{array}{l}\text { Magnetic } \\
\text { properties }\end{array}$ & Diamagnetic $(c<0)$ & Paramagnetic $(c>0)$ & Paramagnetic $(c>0)$ & Paramagnetic $(c>0)$ & $\begin{array}{l}\mathrm{FeOOH} \text { is } \\
\text { superparamagnetic }\end{array}$ \\
\hline SI on T1-wi & $\approx$ or $\downarrow$ & $\begin{array}{l}\approx(\text { or } \downarrow) \text { (no PEDD } \\
\text { interaction) }\end{array}$ & $\uparrow \uparrow$ (PEDD interaction) & $\begin{array}{l}\uparrow \uparrow(\text { PEDD } \\
\text { interaction) }\end{array}$ & $\begin{array}{l}\approx(\text { or } \downarrow) \text { (no PEDD } \\
\text { interaction) }\end{array}$ \\
\hline SI on T2-wi & $\uparrow$ (high water content) & $\begin{array}{l}\downarrow \text { T2 PRE } \\
\text { (susceptibility effect) }\end{array}$ & $\begin{array}{l}\downarrow \downarrow \text { T2 PRE } \\
\text { (susceptibility effect) }\end{array}$ & $\uparrow \uparrow$ No T2 PRE & $\begin{array}{l}\downarrow \downarrow \text { T2 PRE (susceptibility } \\
\text { effect) }\end{array}$ \\
\hline
\end{tabular}

Notes: $\mathrm{Hb}$ hemoglobin, $e$ - electrons, $\mathrm{FeOOH}$ ferric oxyhydroxide, $\uparrow=$ increased SI relative to normal gray matter, $\downarrow=$ decreased SI relative to normal gray matter

\subsubsection{Diffuse Axonal Injury (DAI)}

Diffuse axonal injury is a common type of primary neuronal injury in patients with severe head trauma with an incidence up to $50 \%$ of trauma victims [30,32]. DAI occurs when the brain is exposed to shear-strain forces that leads to lesions at interfaces between two adjacent tissues with different densities or rigidities, such as gray and white matter [33] or areas where the brain is relatively anchored to an adjacent structure, such as the cerebral or cerebellar peduncles or corpus callosum. Predominantly affected areas in decreasing order of frequency are: gray-white matter junction, corpus callosum, basal ganglia, brainstem, and mesencephalon. The severity of the lesions increases towards the cerebellum, whereas axonal injury in the brainstem is considered to be an indicator for degeneration to coma in DAI $[8,33]$.

Its' important clinical relevance and various clinical manifestations have contributed to the development of radiological imaging techniques for detection of DAI. As mentioned, DAI is a common primary injury in brain trauma and CT examination is still the mode of choice in severe trauma patients in the acute phase because of its great value in detecting petechial hemorrhagic lesions, fractures and because of its rapid and convenient acquisition. Unfortunately, CT significantly underestimates the extent and number of DAI lesions, especially of non-hemorrhagic lesions [34] (Fig. 7.10). Therefore, whenever there is a discrepancy between the clinical status of the patient and the CT findings, MRI can provide very important information. In the early stage, diffusion-weighted images are of great importance to detect DAI. In addition, FLAIR sequences are useful for the detection of areas of gliosis. Gradient-echo sequences (GRE) and more recently susceptibility-weighted imaging (SWI) are also superior to $\mathrm{CT}$ in subacute or chronic hemorrhagic head injuries because of paramagnetic blood degradation products [33, 34].

New advanced MRI techniques like diffusion tensor imaging (DTI) offer more sensitive detection and differentiation of DAI. In DTI, the specific water diffusion direction in the white matter is used to detect microstructural conditions that result in restriction in the diffusion of the molecules and alter the values seen on FA (fractional anisotropy) maps [35, 36]. A recent study showed that DTI is a very qualitative and useful way for clinical evaluation of DAI. The authors found decreased anisotropy in the corpus callosum even in patients with normal results on FLAIR and GRE [37]. Multiple additional studies demonstrate the utility of DTI, but application to individual patients remains challenging because of a wide number of variables [38]. DTI and the derived FA values remain an important research tool, and are being widely investigated to determine what value they may provide in the individual patient. For the present time, these remain largely research tools.

\subsection{Vessel Injury}

\subsubsection{Carotid Artery-Cavernous Sinus Fistula (CCF)}

In the traumatic carotid artery-cavernous sinus fistula $(\mathrm{CCF})$, there occurs a direct communication between the cavernous segment of the internal carotid artery (ICA) and the cavernous sinus. The underlying cause is often a laceration of the ICA due to blunt or penetration head trauma. The fistula leads to engorgement and dilatation of the cavernous sinus with successive congestion of the superior ophthalmic vein (SOV) and inferior petrosal sinus [28]. 

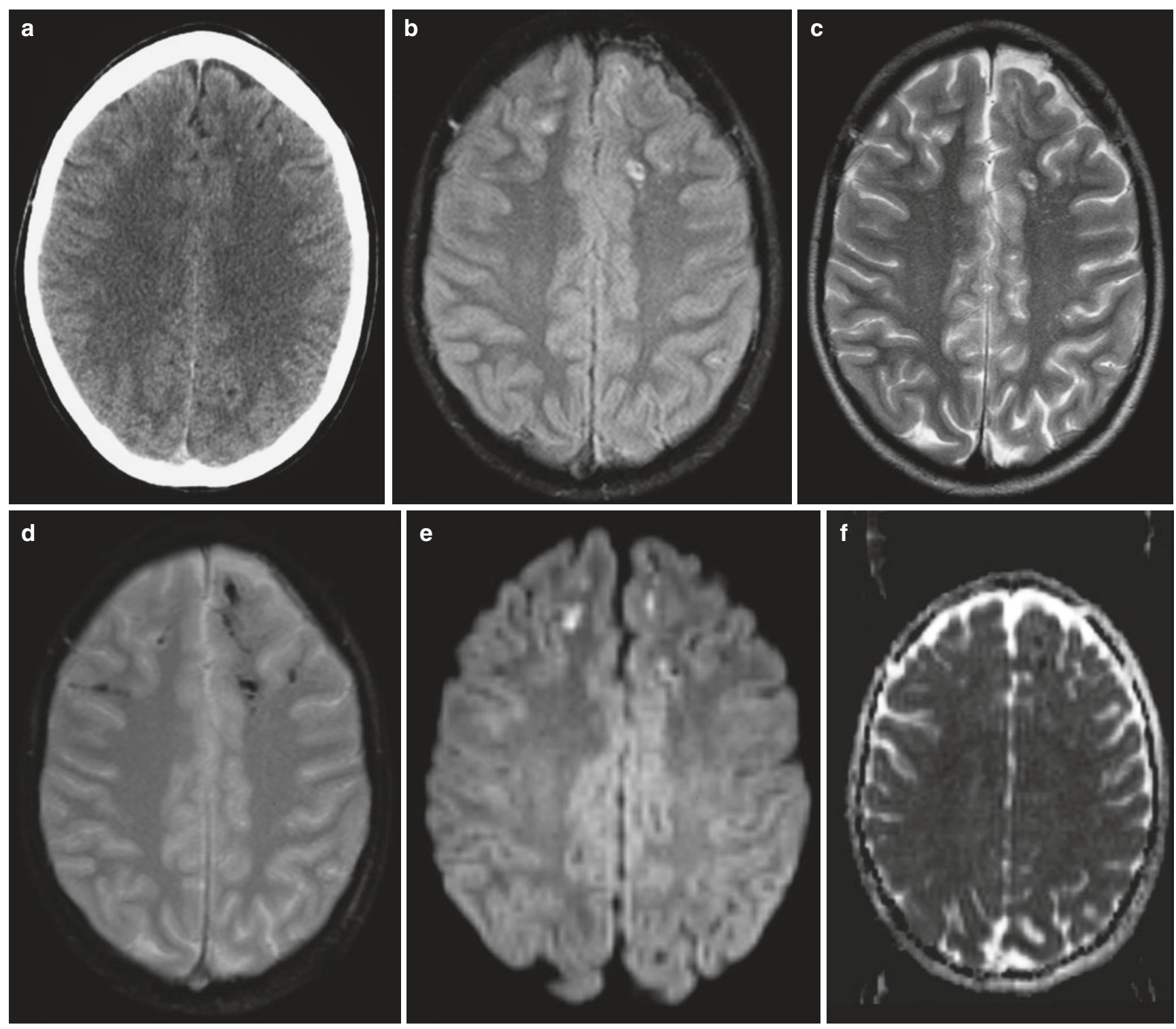

Fig. 7.10 (a-f) Diffuse axonal injuries in a 14-year-old boy, 4 days after a motor vehicle accident: (a) axial non-contrast CT-scan; (b) axial turbo-FLAIR image; (c) axial TSE T2-weighted image; (d) axial gradient-echo FLASH T2*-weighted image $(\mathrm{TE}=25 \mathrm{~ms})$; (e) axial diffusion-weighted image (DWI) with $b=1000$; (f) axial apparent diffusion coefficient (ADC) map. The non-contrast CT-scan shows several punctate petechial hemorrhages at the gray-white matter junction

Specific imaging signs of CCF are enlargement of the cavernous sinus or ipsilateral SOV on CT or MR and multiple flow-voids on MRI. MRA may demonstrate arterialized flow in the cavernous sinus or SOV.

\subsubsection{Traumatic Aneurysms}

Traumatic intracranial aneurysms are rare and represent $<1 \%$ of all aneurysms. They are most common in children [39]. Predominant locations are the cavernous and infraclinoid segment of ICA, as well as along the anterior cerebral artery.

of the frontal lobes. These lesions are hyperintense on turbo-FLAIR and T2-weighted images. On the T2*-weighted image, multiple hypointense hemosiderin deposits are seen at the gray-white matter junction and in the corpus callosum. The appearance, multiplicity, and topographical distribution are typical of hemorrhagic shearing injuries. On the DWI scan, the lesions are hyperintense, and on the ADC maps, the lesions are hypointense, indicating restricted diffusion

The gold-standard in imaging of traumatic aneurysms is cerebral angiography, but CT angiography (CTA) is widely used because of its speed and ease of acquisition [40].

\subsubsection{Traumatic Vascular Dissection}

Traumatic vascular dissections are unusual complications of significant head injury. The injury is caused by a tear in the intimal layer of an artery, resulting in several potential findings, notably diversion of blood flow into a potential "false" lumen within the media. Dissection occurs as a consequence of con- 
tiguous bony injury (fractures), rotational forces and torsion of the vessel in blunt head trauma or less frequently with penetrating trauma [41]. The incidence in blunt trauma victims is $0.86 \%$ for ICA and $0.53 \%$ for traumatic vertebral artery dissections. A common indication for vascular imaging in this setting is fractures of the skull base extending through the carotid canal.

Again, different techniques may provide a diagnosis of vessel dissection. Conventional angiography remains a useful examination. Although the intramural hematoma cannot be visualized, the "string-sign" and a "flame-shaped tapering" are common radiological features [42]. Ultrasound examinations, especially B-mode and Color-flow Doppler, are also increasingly used in detection of traumatic dissections. To detect subtle luminal abnormalities or wall abnormalities in dissection, both CT and MRI, as well as CTA and MRA are superior to catheter angiography.

\subsection{Secondary Lesions}

\subsubsection{Definition}

Secondary brain damage results from the posttraumatic pathophysiologic cascade that follows the initial injury and contributes to delayed tissue injury and neuronal loss.

\subsubsection{Intracranial Hypertension}

Intracranial hypertension may occur after severe cerebral injury and can be a significant finding, resulting in progressive neural dysfunction. After traumatic brain injury, intracranial hypertension may be caused by cumulative edema, hemorrhage, or swelling after contusion. The presence of any of these signs is suspicious: loss of gray-white junction indicating cerebral edema, midline shift, a significant hematoma, herniation, or change in ventricular shape or size [28].

\subsubsection{Brain Herniation (Table 7.4)}

Cerebral herniation is the most common and dangerous secondary effect of increased ICP [8]. Cerebral herniation is the most common secondary effect of an expanding intracranial mass. Due to the herniation the subarachnoid spaces and basal cisterns become obliterated, hydrocephalus develops, vascular compression may result in brain ischemia, and compression on vital brain tissue may cause profound neurological deficits.

\section{8.2.2 Secondary Brainstem Hemorrhage (Duret Hemorrhage)}

Secondary brainstem hemorrhage (also known as "Duret hemorrhage"), can occur in craniocerebral trauma

Table 7.4 Cerebral herniation types

\begin{tabular}{|c|c|c|c|c|c|c|}
\hline $\begin{array}{l}\text { Type of } \\
\text { cerebral } \\
\text { herniation }\end{array}$ & $\begin{array}{l}\text { Subfalcial h. } \\
\text { (cingulate h.) }\end{array}$ & Tonsillar h. & $\begin{array}{l}\text { Descending } \\
\text { transtentorial h. }\end{array}$ & $\begin{array}{l}\text { Ascending } \\
\text { transtentorial h. }\end{array}$ & Uncal h. & External h. \\
\hline Definition & $\begin{array}{l}\text { Medial } \\
\text { displacement of } \\
\text { cingulate gyrus } \\
\text { under inferior free } \\
\text { margin of the falx }\end{array}$ & $\begin{array}{l}\text { Inferior } \\
\text { displacement of } \\
\text { cerebellar } \\
\text { tonsil(s) through } \\
\text { foramen magnum }\end{array}$ & $\begin{array}{l}\text { Downward shift of } \\
\text { diencephalon, } \\
\text { mesencephalon, and } \\
\text { upper brainstem }\end{array}$ & $\begin{array}{l}\text { Superior } \\
\text { displacement of } \\
\text { the vermis } \\
\text { through the } \\
\text { tentorial incisura }\end{array}$ & $\begin{array}{l}\text { Herniation of medial } \\
\text { temporal lobe through } \\
\text { tentorial notch }\end{array}$ & $\begin{array}{l}\text { Brain tissue } \\
\text { extrudes externally } \\
\text { through a skull } \\
\text { defect }\end{array}$ \\
\hline Cause & $\begin{array}{l}\text { Supratentorial } \\
\text { mass (e.g., EDH, } \\
\text { SDH, } \\
\text { hemispheric mass } \\
\text { lesion, ...) }\end{array}$ & $\begin{array}{l}\text { Posterior fossa } \\
\text { mass lesions or } \\
\text { supratentorial } \\
\text { mass effect }\end{array}$ & $\begin{array}{l}\text { Increasing } \\
\text { supratentorial mass } \\
\text { effect }\end{array}$ & $\begin{array}{l}\text { Posterior fossa } \\
\text { mass lesion } \\
\text { (tumor) }\end{array}$ & $\begin{array}{l}\text { Temporal lobe mass } \\
\text { lesion, e.g., focal } \\
\text { hematoma }\end{array}$ & $\begin{array}{l}\text { Increased ICP in } \\
\text { association with a } \\
\text { traumatic or } \\
\text { surgical skull } \\
\text { defect }\end{array}$ \\
\hline Imaging & $\begin{array}{l}\text { - Mass lesion } \\
\text { - Bowing of falx } \\
\text { - Compression of } \\
\text { ipsilateral } \\
\text { lateral ventricle } \\
\text { - Contralateral } \\
\text { ventricle } \\
\text { enlarges due to } \\
\text { obstruction of } \\
\text { the foramen of } \\
\text { Monro }\end{array}$ & $\begin{array}{l}\text { - Downward } \\
\text { displacement } \\
\text { of cerebellar } \\
\text { tonsils below } \\
\text { level of } \\
\text { foramen } \\
\text { magnum } \\
\text { - Obliteration of } \\
\text { cisterna magna }\end{array}$ & $\begin{array}{l}\text { - Obliteration of } \\
\text { peri-mesencephalic } \\
\text { cisterns with } \\
\text { complete plugging } \\
\text { of tentorial incisura } \\
\text { - Downward shift of } \\
\text { pineal calcification } \\
\text { - Brainstem is } \\
\text { foreshortened } \\
\text { (sagittal plane) and } \\
\text { compressed (axial } \\
\text { plane) }\end{array}$ & $\begin{array}{l}\text { - Fourth ventricle } \\
\text { becomes } \\
\text { obliterated } \\
\text { - Effacement of } \\
\text { the superior } \\
\text { cerebellar and } \\
\text { quadrigeminal } \\
\text { cisterns }\end{array}$ & $\begin{array}{l}\text { - Obliteration of the } \\
\text { suprasellar cistern } \\
\text { - Shift of } \\
\text { mesencephalon to } \\
\text { opposite side } \\
\text { - Widening of } \\
\text { ipsilateral CPA } \\
\text { cistern } \\
\text { - Obstructive } \\
\text { hydrocephalus (due } \\
\text { to aqueductal } \\
\text { obstruction) }\end{array}$ & $\begin{array}{l}\text { - Extracranial } \\
\text { displacement of } \\
\text { brain tissue } \\
\text { - Bone defect can } \\
\text { be }\end{array}$ \\
\hline $\begin{array}{l}\text { Compression } \\
\text { of vascular } \\
\text { structures }\end{array}$ & $\begin{array}{l}\text { ACA infarction } \\
\text { (pericallosal and } \\
\text { callosomarginal } \\
\text { arteries) }\end{array}$ & PICA infarction & $\begin{array}{l}\text { PCA compression } \\
\text { leads to occipital lobe } \\
\text { ischemia or infarction }\end{array}$ & $\begin{array}{l}\text { SCA compression } \\
\text { may result in } \\
\text { cerebellar } \\
\text { infarction }\end{array}$ & $\begin{array}{l}\text { Compression of the } \\
\text { contralateral PCA } \\
\text { against the tentorial } \\
\text { edge }\end{array}$ & $\begin{array}{l}\text { Venous obstruction } \\
\text { may result in } \\
\text { venous infarction } \\
\text { (propensity to } \\
\text { hemorrhage) }\end{array}$ \\
\hline $\begin{array}{l}\text { Other } \\
\text { complications }\end{array}$ & $\begin{array}{l}\text { Intracranial } \\
\text { hypertension may } \\
\text { cause descending } \\
\text { transtentorial h }\end{array}$ & $\begin{array}{l}\text { Hydrocephalus } \\
\text { and } \\
\text { syringomyelia }\end{array}$ & $\begin{array}{l}\text { "Duret" brainstem } \\
\text { hemorrhage } \\
\text { (disruption of } \\
\text { perforating arteries to } \\
\text { brainstem) }\end{array}$ & $\begin{array}{l}\text { Hydrocephalus } \\
\text { due to } \\
\text { compression of } \\
\text { the aqueduct }\end{array}$ & $\begin{array}{l}\text { - Can progress to } \\
\text { descending } \\
\text { transtentorial h. } \\
\text { - Obstructive } \\
\text { hydrocephalus }\end{array}$ & $\begin{array}{l}\text { Pressure necrosis } \\
\text { with swelling of } \\
\text { the adjacent brain } \\
\text { at the margins of } \\
\text { the defect }\end{array}$ \\
\hline
\end{tabular}


patients with rapidly evolving descending cerebral herniation [43]. It is evident on CT as a hyperdense brainstem lesion, typically found in lower mesencephalon and ventral pons (Fig. 7.6). It is not clear whether the origin is arterial or venous, but in the majority of cases the outcome is fatal $[8,43]$.

\subsubsection{Ischemic Lesions and Infarction}

Posttraumatic ischemic lesions are common craniocerebral trauma complications with poor clinical outcome. MRI plays an important role in diagnosing this condition by demonstrating multiple areas of abnormal signal intensity on T2-weighted and FLAIR images [8]. On diffusion-weighted scans, these lesions are seen in the acute phase as hyperintense signal with corresponding hypointense signal on ADC [44]. Of all posttraumatic ischemic lesions, the classic lesion is an ipsilateral posterior cerebral artery infarction in the setting of significant supratentorial mass effect, secondary to any traumatic lesion with mass effect. The causative lesion may be an extra-axial hemorrhage or intracranial hemorrhage associated with edema and mass effect. The posterior cerebral artery may be compressed and transiently occluded between the brain and the free edge of the tentorium. Other intracranial arteries may be occluded or compromised secondary to herniation, including the middle and anterior cerebral arteries [45].

\subsubsection{Infections}

The risk of local wound infections, meningitis, ventriculitis, or cerebral abscess are particularly high among penetrating head trauma because of the presence of contaminated foreign objects, skin, hair, and bone fragments driven into the brain tissue along the projectile track [46].

\subsection{Posttraumatic Sequelae}

\subsubsection{Posttraumatic Encephalomalacia}

The term "posttraumatic encephalomalacia" refers to loss of brain tissue after craniocerebral trauma. Gross pathology shows weakening or cystic cavitation of brain tissue, with blurred cortical margins and surrounded by gliotic scar tissue. The basal part of the temporal lobes and anterior pole of the temporal lobes are most frequently affected. CT scans show hypodense areas of tissue loss, particularly in these parts of the brain. On MRI, encephalomalacia is identified as (multi-) cystic areas of tissue loss, surrounded by an irregular rim of gliosis, best seen on FLAIR images as a hyperintense rim (Fig. 7.11). Posttraumatic encephalomalacia is a very serious condition, resulting in life-long disability, neurological dysfunction, epilepsy, or even death in some cases. Another common form of posttraumatic encephalomalacia involves the olfactory nerve, which is frequently injured in shear injury.
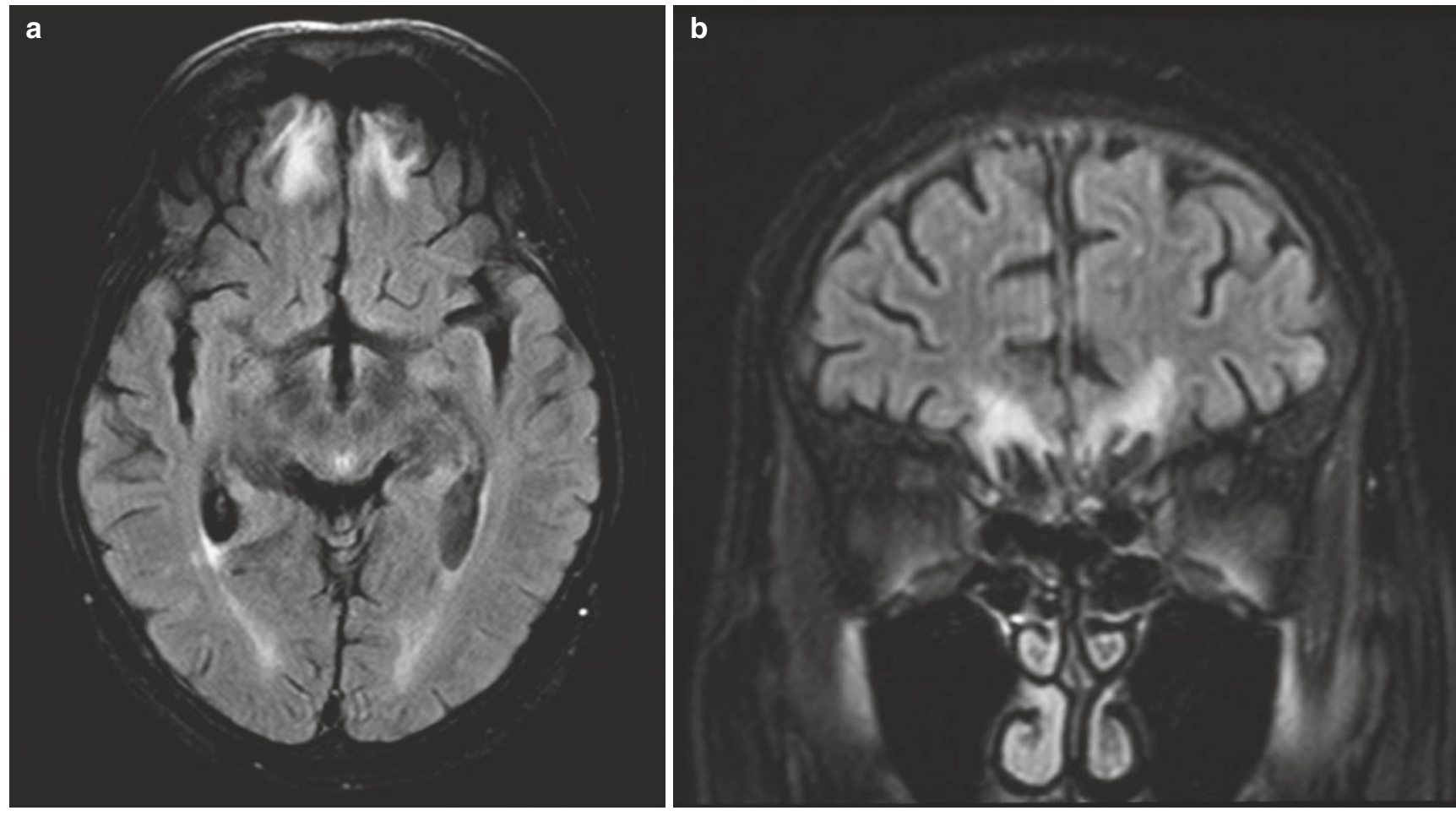

Fig. 7.11 (a, b) Posttraumatic encephalomalacia and gliosis. Axial (a) and coronal (b) turbo-FLAIR images with spectral fat saturation. MRI performed 4 years after severe head injury. There are areas of posttraumatic tissue loss in the basal part of the frontal lobes bilaterally. The areas of tissue loss are surrounded by gliosis, which is hyperintense on the FLAIR images. In addition, there are old diffuse axonal injuries, seen as gliotic foci at the gray-white matter interface, e.g., in the upper part of the left frontal lobe 


\subsubsection{Growing Skull Fracture}

A growing skull fracture is a rare but well-known complication of pediatric head trauma [47]. Its incidence ranges from $<0.05 \%$ to $1.6 \%$ [48]. CT and MRI findings include a diastatic fracture and brain herniation through the skull defect; it can also be accompanied by cystic lesions (meningocele) within the fracture and encephalomalacia [48].

\subsubsection{Traumatic CSF Leaks}

Traumatic cerebrospinal leakage is a complication seen in $2 \%$ of all head-injured patients and in $12-30 \%$ of cases of basilar skull fractures [49]. The most common locations are the cribriform plate (forming the roof of the ethmoid) and the walls of the frontal sinus [50]. Intracranial air may be an important sign. Careful evaluation of fractures that are contiguous to sinuses is key to making a correct diagnosis. Persistent opacification of sinuses contiguous to a fracture are of particular suspicion. Suggesting the presence of a CSF leak will usually result in testing of fluid in the contiguous sinus for the presence of beta- 2 transferrin, a dependable marker of CSF.

\subsubsection{Diabetes Insipidus}

The prevalence of central diabetes insipidus (DI) after TBI is $1.7-26 \%$, often resulting from injury or transection of the infundibulum. MRI is the technique of choice for pituitary imaging. A sagittal T1-weighted image demonstrates a posterior pituitary "bright spot" in healthy individuals. The absence of this "bright spot" in diabetes insipidus is a nonspecific sign of DI [51]. In addition to the absence of this sign, an ectopic "bright spot" in the proximal stump of the transected, retracted proximal stalk or hypothalamus may be identified. If there is clinical suspicion of trauma-related DI, a dedicated pituitary examination is the appropriate examination.

\subsection{Quantitative Imaging in Patients with Traumatic Brain Injury}

\subsubsection{Diffusion Weighted Imaging (DWI) with ADC Maps}

Diffusion-weighted imaging measures the motion of water molecules and thus helps visualize the physiologic state in the brain [8]. There are physiologic phase-shifts or signal loss due to this normal semi-random motion of water molecules. In distinction, areas with abnormal diffusion reflect alterations in the normal water diffusion and appear bright on DWI [29]. The apparent diffusion coefficient (ADC) values indicate the decrease in the diffusion with corresponding hypointense signal on ADC maps [29]. DWI has become an important tool in diagnosing TBI, acute stroke, and white matter diseases [8].

\subsubsection{Diffusion Tensor Imaging (DTI), Diffusion Kurtosis Imaging (DKI)}

Diffusion tensor Imaging (DTI) is derived from specialized DWI with multiple directions, and can measure not only the degree, but also the direction of water diffusion [52]. It allows in-vivo visualization of the integrity of white matter tracts. The main application is in diffuse axonal injury.

Diffusion kurtosis Imaging (DKI) is an extended technique, derived from DTI, and allows diffusional kurtosis to be evaluated using diffusion-weighted imaging techniques [53]. With DKI, both gray and white matter can be evaluated.

\subsubsection{Outcome Prediction with Imaging Parameters}

Imaging is a very important clinical tool for diagnosis, prognosis, and visualizing therapy outcomes following TBI. Although structural imaging techniques such as CT or MRI offer a rapid evaluation of the brain status and may help predict survival, more information is necessary. Detailed information of cerebral perfusion has also proven useful in management and in assessing outcomes [29].

Several imaging techniques are available to visualize the brain physiology: CT perfusion, MR perfusion, SPECT, fMRI (functional MRI), PET, and MRS (MR Spectroscopy). While obviously important research tools, these techniques are occasionally finding their way into clinical imaging to answer clinical questions.

MRI sequences like DTI, FLAIR, GRE/SWI, and DWI are increasingly used in many research models predicting outcome [54].

\subsection{Conclusion}

Imaging studies represent an essential element in the management of patients with significant neurologic trauma. Diagnosis of the extent of the initial injury is critical to triage patients to surgical or non-surgical management. Repeated follow up to determine potential secondary injury patterns and also determine the success of management schemes are of significant value and improve patient outcomes. Imaging techniques have shown considerable promise in improving 
our knowledge of the patterns and significance of intracranial injury and in suggesting and monitoring therapies to treat these patients and determine their prognosis.

\section{Take Home Messages}

- A rapid and thorough CT examination of the acutely traumatized patient is standard of care in major trauma centers.

- Develop a protocol for urgent CT screening and reporting of major trauma patients.

- Rapid access to imaging technologies is critical to good outcomes in patients who have been significantly injured.

- If the CT study is not adequate to explain the patient's mental status, MR is the next most important examination to be performed.

\section{References}

1. Maas AI, Stocchetti N, Bullock R. Moderate and severe traumatic brain injury in adults. Lancet Neurol. 2008;7(8):728-41.

2. Tagliaferri F, Compagnone C, Korsic M, Servadei F, Kraus J. A systematic review of brain injury epidemiology in Europe. Acta Neurochir. 2006;148(3):255-68.

3. Le TH, Gean AD. Neuroimaging of traumatic brain injury. Mt Sinai J Med. 2009;76(2):145-62.

4. Jones TR, Kaplan RT, Lane B, Atlas SW, Rubin GD. Single- versus multi-detector row $\mathrm{CT}$ of the brain: quality assessment. Radiology. 2001;219(3):750-5.

5. Langford S, Panigrahy A, Narayanan S, Hwang M, Fitz C, Flom L, Lee VK, Zuccoli G. Multiplanar reconstructed CT images increased depiction of intracranial hemorrhages in pediatric head trauma. Neuroradiology. 2015;57(12):1263-8.

6. Bykowski J, Wong W. Angiographic evaluation and treatment for head and neck vascular injury. Appl Radiol. 2012;41(3):10-6.

7. Provenzale J. Imaging of traumatic brain injury: a review of the recent medical literature. AJR Am J Roentgenol. 2010;194(1):16-9.

8. Parizel PM, Van Goethem JW, Ozsarlak O, Maes M, Phillips $\mathrm{CD}$. New developments in the neuroradiological diagnosis of craniocerebral trauma. Eur Radiol. 2005;15(3):569-81.

9. Yen K, Vock P, Tiefenthaler B, Ranner G, Scheurer E, Thali MJ, Zwygart K, Sonnenschein M, Wiltgen M, Dirnhofer R. Virtopsy: forensic traumatology of the subcutaneous fatty tissue; multislice computed tomography (MSCT) and magnetic resonance imaging (MRI) as diagnostic tools. J Forensic Sci. 2004;49(4):799-806.

10. Malli N, Ehammer T, Yen K, Scheurer E. Detection and characterization of traumatic scalp injuries for forensic evaluation using computed tomography. Int J Legal Med. 2013;127(1):195-200.

11. Hofman PA, Nelemans P, Kemerink GJ, Wilmink JT. Value of radiological diagnosis of skull fracture in the management of mild head injury: meta-analysis. J Neurol Neurosurg Psychiatry. 2000;68(4):416-22.

12. Nakahara K, Shimizu S, Utsuki S, Oka H, Kitahara T, Kan S, Fujii $\mathrm{K}$. Linear fractures occult on skull radiographs: a pitfall at radiological screening for mild head injury. J Trauma. 2011;70(1):180-2.

13. Tallon JM, Ackroyd-Stolarz S, Karim SA, Clarke DB. The epidemiology of surgically treated acute subdural and epidural hemato- mas in patients with head injuries: a population-based study. Can J Surg. 2008;51(5):339-45.

14. Parizel PM, Phillips CD. Neuroradiological diagnosis of craniocerebral trauma: current concepts. In: Hodler J, von Schulthess GK, Zollikofer CL, editors. Diseases of the brain, head \& neck, spine 2012-2015. Basel: Springer; 2012.

15. Al-Nakshabandi NA. The swirl sign. Radiology. 2001;218(2):433.

16. Gean AD, Fischbein NJ, Purcell DD, Aiken AH, Manley GT, Stiver SI. Benign anterior temporal epidural hematoma: indolent lesion with a characteristic CT imaging appearance after blunt head trauma. Radiology. 2010;257(1):212-8.

17. Senturk S, Guzel A, Bilici A, Takmaz I, Guzel E, Aluclu MU, Ceviz A. CT and MR imaging of chronic subdural hematomas: a comparative study. Swiss Med Wkly. 2010;140(23-24):335-40.

18. Honda Y, Sorimachi T, Momose H, Takizawa K, Inokuchi S, Matsumae M. Chronic subdural haematoma associated with disturbance of consciousness: significance of acute-on-chronic subdural haematoma. Neurol Res. 2015;37(11):985-92.

19. León-Carrión J, Domínguez-Morales Mdel R, Barroso y Martín JM, Murillo-Cabezas F. Epidemiology of traumatic brain injury and subarachnoid hemorrhage. Pituitary. 2005;8(3-4):197-202.

20. Fainardi E, Chieregato A, Antonelli V, Fagioli L, Servadei F. Time course of CT evolution in traumatic subarachnoid haemorrhage: a study of 141 patients. Acta Neurochir. 2004;146(3):257-63.

21. Verma RK, Kottke R, Andereggen L, Weisstanner C, Zubler C, Gralla J, Kiefer C, Slotboom J, Wiest R, Schroth G, Ozdoba C, El-Koussy M. Detecting subarachnoid hemorrhage: comparison of combined FLAIR/SWI versus CT. Eur J Radiol. 2013;82(9): $1539-45$.

22. LeRoux PD, Haglund MM, Newell DW, Grady MS, Winn HR. Intraventricular hemorrhage in blunt head trauma: an analysis of 43 cases. Neurosurgery. 1992;31(4):678-84.

23. Sohn CH, Baik SK, Lee HJ, Lee SM, Kim IM, Yim MB, Hwang JS, Lauzon ML, Sevick RJ. MR imaging of hyperacute subarachnoid and intraventricular hemorrhage at 3T: a preliminary report of gradient echo T $2 *$-weighted sequences. AJNR Am J Neuroradiol. 2005;26(3):662-5.

24. Wu Z, Li S, Lei J, An D, Haacke EM. Evaluation of traumatic subarachnoid hemorrhage using susceptibility-weighted imaging. AJNR Am J Neuroradiol. 2010;31(7):1302-10.

25. Toyama Y, Kobayashi T, Nishiyama Y, Satoh K, Ohkawa M, Seki K. CT for acute stage of closed head injury. Radiat Med. 2005;23(5):309-16.

26. Alahmadi H, Vachhrajani S, Cusimano MD. The natural history of brain contusion: an analysis of radiological and clinical progression. J Neurosurg. 2010;112(5):1139-45.

27. Kurland D, Hong C, Aarabi B, Gerzanich V, Simard JM. Hemorrhagic progression of a contusion after traumatic brain injury: a review. J Neurotrauma. 2012;29(1):19-31.

28. Lee B, Newberg A. Neuroimaging in traumatic brain imaging. NeuroRx. 2005;2(2):372-83.

29. Coles JP. Imaging after brain injury. Br J Anaesth. 2007;99(1):49-60.

30. Besenski N. Traumatic injuries: imaging of head injuries. Eur Radiol. 2002;12(6):1237-52.

31. Drew LB, Drew WE. The contrecoup-coup phenomenon: a new understanding of the mechanism of closed head injury. Neurocrit Care. 2004;1(3):385-90.

32. Hammoud DA, Wasserman BA. Diffuse axonal injuries: pathophysiology and imaging. Neuroimaging Clin N Am. 2002; 12(2):205-16.

33. Li XY, Feng DF. Diffuse axonal injury: novel insights into detection and treatment. J Clin Neurosci. 2009;16(5):614-9.

34. Parizel PM, Ozsarlak, Van Goethem JW, van den Hauwe L, Dillen C, Verlooy J, Cosyns P, De Schepper AM. Imaging findings in diffuse axonal injury after closed head trauma. Eur Radiol. 1998;8(6):960-5. 
35. Niogi SN, Mukherjee P, Ghajar J, Johnson C, Kolster RA, Sarkar R, Lee H, Meeker M, Zimmerman RD, Manley GT, McCandliss BD. Extent of microstructural white matter injury in postconcussive syndrome correlates with impaired cognitive reaction time: a 3T diffusion tensor imaging study of mild traumatic brain injury. AJNR Am J Neuroradiol. 2008;29(5):967-73.

36. Hurley RA, McGowan JC, Arfanakis K, Taber KH. Traumatic axonal injury: novel insights into evolution and identification. J Neuropsychiatry Clin Neurosci. 2004;16(1):1-7.

37. Chan JH, Tsui EY, Peh WC, Fong D, Fok KF, Leung KM, Yuen MK, Fung KK. Diffuse axonal injury: detection of changes in anisotropy of water diffusion by diffusion-weighted imaging. Neuroradiology. 2003;45(1):34-8.

38. Hulkower MB, Poliak DB, Rosenbaum SB, Zimmerman ME, Lipton ML. A decade of DTI in traumatic brain injury: 10 years and 100 articles later. AJNR Am J Neuroradiol. 2013;34(11):2064-74.

39. Larson PS, Reisner A, Morassutti DJ, Abdulhadi B, Harpring JE. Traumatic intracranial aneurysms. Neurosurg Focus. 2000;8(1):e4.

40. Mao Z, Wang N, Hussain M, Li M, Zhang H, Zhang Q, Zhang P, Zhi X, Ling F. Traumatic intracranial aneurysms due to blunt brain injury - a single center experience. Acta Neurochir. 2012;154(12):2187-93.

41. Schievink WI. Spontaneous dissection of the carotid and vertebral arteries. N Engl J Med. 2001;344(12):898-906.

42. Caplan LR. Dissections of brain-supplying arteries. Nat Clin Pract Neurol. 2008;4(1):34-42.

43. Parizel PM, Makkat S, Jorens PG, Ozsarlak O, Cras P, Van Goethem JW, van den Hauwe L, Verlooy J, De Schepper AM. Brainstem hemorrhage in descending transtentorial herniation (Duret hemorrhage). Intensive Care Med. 2002;28(1):85-8.
44. Parizel PM, Demey HE, Veeckmans G, Verstreken F, Cras P, Jorens PG, De Schepper AM. Early diagnosis of cerebral fat embolism syndrome by diffusion-weighted MRI (starfield pattern). Stroke. 2001;32(12):2942-4.

45. Server A, Dullerud R, Haakonsen M, Nakstad PH, Johnsen UL, Magnaes B. Post-traumatic cerebral infarction. Neuroimaging findings, etiology and outcome. Acta Radiol. 2001;42(3):254-60.

46. Kazim SF, Shamim MS, Tahir MZ, Enam SA, Waheed S. Management of penetrating brain injury. J Emerg Trauma Shock. 2011;4(3):395-402.

47. Drapkin AJ. Growing skull fracture: a posttraumatic neosuture. Childs Nerv Syst. 2006;22(4):394-7.

48. Ersahin Y, Gülmen V, Palali I, Mutluer S. Growing skull fractures (craniocerebral erosion). Neurosurg Rev. 2000;23(3):139-44.

49. Friedman JA, Ebersold MJ, Quast LM. Post-traumatic cerebrospinal fluid leakage. World J Surg. 2001;25(8):1062-6.

50. Hofmann E, Behr R, Schwager K. Imaging of cerebrospinal fluid leaks. Klin Neuroradiol. 2009;19(2):111-21.

51. Makulski DD, Taber KH, Chiou-Tan FY. Neuroimaging in posttraumatic hypopituitarism. J Comput Assist Tomogr. 2008; 32(2):324-8.

52. Xiong KL, Zhu YS, Zhang WG. Diffusion tensor imaging and magnetic resonance spectroscopy in traumatic brain injury: a review of recent literature. Brain Imaging Behav. 2014;8(4):487-96.

53. Jensen JH, Helpern JA. MRI quantification of non-Gaussian water diffusion by kurtosis analysis. NMR Biomed. 2010;23(7):698-710.

54. Huisman TA, Schwamm LH, Schaefer PW, Koroshetz WJ, ShettyAlva N, Ozsunar Y, Wu O, Sorensen AG. Diffusion tensor imaging as potential biomarker of white matter injury in diffuse axonal injury. AJNR Am J Neuroradiol. 2004;25(3):370-6.

Open Access This chapter is licensed under the terms of the Creative Commons Attribution 4.0 International License (http://creativecommons. org/licenses/by/4.0/), which permits use, sharing, adaptation, distribution and reproduction in any medium or format, as long as you give appropriate credit to the original author(s) and the source, provide a link to the Creative Commons license and indicate if changes were made.

The images or other third party material in this chapter are included in the chapter's Creative Commons license, unless indicated otherwise in a credit line to the material. If material is not included in the chapter's Creative Commons license and your intended use is not permitted by statutory regulation or exceeds the permitted use, you will need to obtain permission directly from the copyright holder. 